\title{
Non-Economic Factors in Violence: Evidence from Organized Crime, Suicides and Climate in Mexico*
}

\author{
Ceren Baysan, Marshall Burke, Felipe González, Solomon Hsiang, Edward Miguel
}

\begin{abstract}
Organized intergroup violence is almost universally modeled as a calculated act motivated by economic factors. In contrast, it is generally assumed that non-economic factors, such as an individual's emotional state, play a role in many types of interpersonal violence, such as "crimes of passion." We ask whether non-economic factors can also explain the well-established relationship between temperature and violence in a unique context where intergroup killings by drug-trafficking organizations (DTOs) and other interpersonal homicides are separately documented. A constellation of evidence, including the limited influence of a cash transfer program as well as comparisons with both other DTO crime and suicides, indicate that economic factors only partially mitigate the relationship between temperature and violence that we estimate in Mexico. We argue that non-economic psychological and physiological factors that are affected by temperature, modeled here as a "taste for violence," likely play an important role in causing both interpersonal and intergroup violence.
\end{abstract}

*Affiliations: Baysan at University of Essex; Burke at Stanford University; González at Pontificia Universidad Católica de Chile; Hsiang and Miguel at University of California, Berkeley (contact email: emiguel@berkeley.edu). We would like to thank Melissa Dell for discussing our paper and Lucas Davis for data sharing. We also thank conference participants at PacDev UC San Diego (2015) and the AEA Conference on the Economics of Violence (2016), and seminar participants at the American Geophysical Union, Center for Effective Global Action (CEGA), PUC-Chile, Stanford, UC Berkeley, University of Chicago, Stockholm University, and University of Toronto for comments and suggestions. 


\section{Introduction}

The positive relationship between changes in temperature and violence has now been documented across diverse geographic settings and for many types of human conflict, ranging from institutional collapse to civil war, riots, and crime. ${ }^{1}$ Yet the mechanisms underlying these estimates remain poorly understood, and are of primary concern in order to inform policies that can mitigate higher rates of conflict as temperature continues to rise (Dell et al., 2014). While studies in the economics and psychology literature demonstrate that rising temperatures can amplify interpersonal violence and aggression even when economic factors are held constant, the role of non-economic factors in explaining broader patterns of intergroup conflict remains unexplored. Such group-level conflict remains a key source of premature death and livelihood loss throughout much of the developing world, and is almost exclusively modeled as the result of a strategic and rational calculation, with physiological or psychological factors not assumed to play an important role. Understanding whether this assumption is correct is critical for a broader understanding of the origins of conflict, and an understanding of climate's role in a range of conflict outcomes.

Why might changes in temperature induce violence and conflict, and what can this tell us about the broader underpinnings of violence? To date, economic models of violence treat interpersonal and intergroup violence as different phenomena. Instances of interpersonal violence, such as assault and murder, are generally thought of as "crimes" that may have either an economic or emotional motivation - assaulting an individual in order to expropriate their assets is clearly economic, whereas "crimes of passion" presume emotional factors. In contrast, violence between groups of individuals is almost always modeled as a strategic calculation where the economic costs of conflict are weighed against potential gains. In many cases, this decision to focus on economic factors is well-motivated and generates sharp predictions that often agree with data. ${ }^{2}$

Accordingly, economists often interpret the temperature-conflict relationship as largely an income effect: hotter temperatures and lower rainfall are known to lower incomes, particularly in agricultural areas, and this in turn could temporarily lower the opportunity cost of participation in violence. In an early study, Miguel et al. (2004) provide empirical evidence

\footnotetext{
${ }^{1} \mathrm{~A}$ meta-analysis finds that interpersonal and intergroup conflict rise by approximately $4 \%$ and $10 \%$ for each 1 standard deviation increase in temperature, respectively (Hsiang et al., 2013). This implies a large historical role for temperature variation in shaping conflict risk, and an even larger potential role for future climate change in shaping these outcomes, given the anticipated $>4 \sigma$ increase in temperature expected across much of the tropics over the next century.

${ }^{2}$ See, for example, Collier and Hoeffler (1998), Miguel et al. (2004), Angrist and Kugler (2008), Berman et al. (2011), Besley and Persson (2011), Dube and Vargas (2013), among others.
} 
that rainfall shocks that lower economic growth also increase the likelihood of civil war in Sub-Saharan Africa. Chassang and Padró-i-Miquel (2010) explain this result by developing a bargaining model in which violence occurs when a shock to economic productivity temporarily lowers the opportunity cost to violence, but does not affect the future value of winning the contest.

This economic explanation for a temperature-violence relationship, however, has difficulty accounting for the observed response of individual-level violence to daily or even hourly variations in temperature, as income is unlikely to change over these short periods (Jacob et al., 2007, Card and Dahl, 2009, Larrick and et al, 2011, Ranson, 2014). Vrij et al. (1994) offer perhaps the clearest case, where police officers were observed utilizing more violence during a training exercise when temperature in the room was manipulated to be hotter. ${ }^{3}$ Thus, while interpersonal violence is often conceived of as an action with private costs and benefits that also imposes costs on others (Becker, 1968), and which agents may rationally undertake to affect the allocation of resources (Donohue and Levitt 1998, Chimeli and Soares 2017, Castillo et al. 2018), existing evidence indicates that non-economic factors are at least partially responsible for generating the observed temperature-violence link at the individual level.

Given that most instances of group-level violence are, at the most basic level, implemented by individuals, this then suggests a potential additional role for non-economic factors in intergroup violence. Consider the group member on the front lines of a conflict who is personally implementing violence to further a group's strategic objectives. There are many decision points where non-economic psychological factors could play a role in his decision making, with the individual having some discretion in exactly how much violence to employ when contact with an opponent actually occurs. If the agent personally enjoys violence, she may employ more of it when given some discretion over its use, and if the agent dislikes violence she may employ less. Changes in the opportunity cost of violence will not necessarily be the key determinant of the agent's use of violence. If there are multiple opportunities for non-economic factors to influence the individual's use of violence, then non-economic factors could become important determinants of the level of intergroup conflict.

We propose a unified framework in which both interpersonal and intergroup violence may be influenced by both economic and non-economic factors, although their relative influence may differ (making it ultimately an empirical question). We expand a standard economic

\footnotetext{
${ }^{3}$ In another laboratory experiment, which is unfortunately rather poorly documented, Rohles (1967) reports, "When [participants] were subjected to high temperatures in groups of 48, there was continual arguing needling, agitating, jibing, fist-fighting, threatening, and even an attempted knifing. At lower temperatures or in small groups, this behavior diminished."
} 
model of violence by allowing the aggressor to experience pure consumption value from using violence, which we model as a positive or negative input into utility, depending on the individual's "taste for violence." 4 Introducing this single non-economic factor and allowing it to respond positively to temperature, as indicated by prior analyses, substantially improves the ability of the model to account for observed patterns in the relationship between temperature changes and intergroup violence.

We then test multiple hypotheses generated by this unified model in Mexico, a context where exceptional levels of violence by drug-trafficking organizations (DTOs) motivated law enforcement to gather separate data on intergroup homicides. This allows us to observe variation in comparable group-level and individual-level acts of violence, i.e., homicides in both cases, in a single context where geographical, political, and institutional factors can be "held fixed." This provides a unique opportunity to compare the effect of temperature on both interpersonal and intergroup violence without the comparison being confounded by contextual differences that usually differ between studies. ${ }^{5}$ Such comparisons allow us to consider whether these two types of violence might share a common non-economic mechanism.

Consistent with earlier meta-analyses, we show that higher monthly temperatures have a positive and significant effect on both killings by drug-trafficking organizations (DTOs) and "normal" (non-DTO) homicides in Mexico. Effects in both cases are contemporaneous, large in magnitude, and generalizable across regions in Mexico. We find that a one standard deviation increase in temperature is associated with a $28 \%$ increase in drug-related killings and $5 \%$ increase in regular homicides.

We next use a variety of approaches to investigate whether these results are driven or mitigated by economic factors. We find that economic mechanisms can only partially explain the relationship between temperature and DTO killings, and they have almost no explanatory power in the case of non-DTO homicides. For instance, changes in temperature have no comparable effect on non-violent and primarily economic crimes committed by DTOs, such

\footnotetext{
${ }^{4}$ In a similar vein, Tauchen et al. (1991), Farmer and Tiefenthaler (1997), Bowlus and Seitz (2006), and Aizer (2010) explain domestic violence as expressive behavior that provides positive utility to some men. Their partners tolerate it in return for higher transfers. Card and Dahl (2009) adopt this interpretation of family violence as motivation to consider the role for emotional cues (or "visceral factors") in precipitating violence. They use unexpected losses in football games as the trigger for these emotional cues. A key contribution of our paper is to extend this framework beyond domestic violence and to introduce these psychological factors into the rapidly growing literature on intergroup conflict. Blattman et al. (2017) provide experimental evidence on the role non-cognitive skills and preferences could play in shaping violence.

${ }^{5}$ Hsiang et al. (2013) compare results from 60 studies and find that the average effect of temperature on interpersonal violence differs substantially from the effect on intergroup violence. However, each study only examined one form of violence in a given context, and none were from comparable contexts (e.g., civil war in African countries vs. domestic abuse in Australia), complicating the interpretation of differences across categories of violence.
} 
as extortion and car theft, which we would expect to respond similarly to temperature if both were caused by a single underlying mechanism. Similarly, exogenous variation in the level of government social assistance through the large scale Progresa/Oportunidades program has limited effect in dampening the effect of high temperatures on group conflict. Finally, growing season temperatures matter little for harvest season violence, and other measures of economic conditions and inequality have limited predictive power in explaining the observed temperature-violence relationship.

Data on suicides in Mexico provide further evidence that psychological factors better explain the observed link between temperature and violence. Suicides, which could be thought of as intrapersonal violence, are known to be heavily influenced by psychological factors, and we show that the response of suicide to temperature in Mexico strongly matches the responses of interpersonal and intergroup violence to temperature: the response is linear, contemporaneous, common across regions, not mediated by observable economic factors or Progresa/Oportunidades, and only barely affected by growing season temperatures. We interpret this pattern-matching exercise as further evidence that psychological factors play a role in temperature's effect on group violence

Beyond our primary contribution to the understanding of the channels linking climate and intergroup violence, our work broadens the "spectrum of violence" known to be affected by climatic events (Figure 1). This includes evidence on large-scale institutional responses to climatic change (Haug et al., 2003, Buckley et al., 2010), on more localized intergroup conflict (Harari and Ferrara, 2018, Fetzer et al., 2019, Hsiang et al., 2011, Burke et al., 2009), and on interpersonal conflict (Ranson, 2014, Larrick and et al, 2011, Jacob et al., 2007). To our knowledge, our evidence on gang responses to temperature is novel. Gangs are smaller and less organized than armed militias but larger and more organized than spontaneous groups, such as mobs, both of which have been previously linked to extreme climate. Similarly, we add to a small but growing literature on the link between suicide and climate (Burke et al., 2018, Dixon et al., 2007). By further expanding and filling in this spectrum of social phenomena affected by climate, this work bolsters our understanding of how climatic conditions may affect the peacefulness of modern societies (Hsiang et al., 2013). 


\section{Understanding Violence}

\subsection{Drug trafficking in Mexico}

Drug trafficking organizations in Mexico appeared in the 1990s (Grillo, 2012) and have since grown in size and sophistication, nowadays constituting an industry that earns between 14 and 48 billion USD annually (U.S. State Department, 2009). In addition to trafficking, these organizations engage in extortion and kidnapping (Rios, 2014) and rose from 6 in 2007 to approximately 16 in 2010 (Guerrero, 2012a). ${ }^{6}$

Starting in 2007 drug-related violence has increased dramatically, claiming more than 50,000 lives (Dell, 2015). Following the presidential election of 2006, president Felipe Calderón declared war on drug trafficking organizations. Shortly after this event, crackdowns spread through the country, and violence escalated to unprecedented levels (Merino, 2011, Guerrero, 2011b, Escalante, 2011). Several factors have been offered as causes: (1) Felipe Calderón's crackdowns and captures of DTO leaders (Guerrero, 2010, Chaidez, 2014, Calderón et al., 2015, Dell, 2015, Osorio, 2015); (2) U.S.-Colombia efforts to reduce the supply of drugs (Castillo et al., 2018); and (3) exogenous movements in international crop prices affects the opportunity cost of joining the drug industry (Dube et al., 2016). The relative contribution of each of these factors is, however, a matter of ongoing debate. To our knowledge, this is one of the first papers to link DTO violence to climatic shocks.

To understand drug violence "on the ground," we need to know more about DTO frontline workers, how they were recruited, and how is violence taking place. According to the Secretary of Defense department in Mexico, there are currently more than 500,000 DTO workers, among them more than 75,000 children and adolescents. They are usually recruited through more than 800 recruiting and training centers spread throughout the country (Cruz Santiago et al., 2012), and local economic factors and opportunities seem to be an important explanation behind the individual decision to join, both in rural and urban areas (Dube et al., 2016, Dell et al., 2019). In implementing the DTO's operations - violence, trafficking, and other criminal activities - these are the individuals whose decisions might be affected by climatic factors. Regarding the nature of violence taking place after 2007, Osorio (2015) provides the most comprehensive data. As crackdowns diminished the power of incumbent DTOs, competing organizations exerted effort to take control of these territories (Dell, 2015, Osorio, 2015), resulting in violence between DTOs and with state agents in charge of the

\footnotetext{
${ }^{6}$ Most new organizations are factions of older groups and appear after traditional leaders are arrested or killed (Guerrero, 2012b, Rios, 2013). Guerrero (2011a) discusses the issue of DTO fractionalization in greater detail. See Table A.1 for characteristics of DTOs.
} 
crackdown. In line with this explanation, Osorio (2015) uses text analysis to study national and local newspapers and finds that most violence in this period was between DTOs. While we cannot rule out that non-gang victims are included in our DTO data, evidence in Osorio (2015) suggest that most of the violence recorded as DTO killings was due to gangs fighting gangs.

\section{$2.2 \quad$ Non-economic factors in violence}

A large body of research has dissected the logic of violence and documented the role that economic factors can play (Miguel et al., 2004, Angrist and Kugler, 2008, Berman et al., 2011, Besley and Persson, 2011, Dube and Vargas, 2013). ${ }^{7}$ This work would also seem to provide a prima facie explanation for the now well-documented role that changes in temperature appear to play in instigating violence and human conflict (Hsiang et al., 2013, Burke et al., 2015), given that changes in temperature are also known to induce variation in both agricultural and non-agricultural incomes (Hsiang, 2010, Dell et al., 2012).

Accumulating scientific evidence, however, also points toward an important role for physiological and psychological factors in explaining certain types of human violence, and importantly (for our purposes) also the potential for temperature to shape these non-economic factors. For instance, the psychological roots of intrapersonal violence - i.e., suicide - have been well documented, and the role of temperature in this particular type of violence, as well as in interpersonal human aggression, have been explored by researchers since at least the 1930s. ${ }^{8}$ While scientific understanding of temperature regulation in the human body remains imperfect (e.g., Hammel 1974, Werner 1980, Cooper 2002, and Mekjavic and Eiken 2006)), there is growing evidence that neural structures are directly involved in this process (Benzinger, 1970, Morrison et al., 2008, Ray et al., 2011). This is important because particular neurotransmitters that have been shown to participate in body temperature regulation - in particular, serotonin - have also been linked to mood, emotion, and range of human behaviors (National Institutes of Health, 2011, Lovheim, 2012). For serotonin specifically, there is growing consensus that decreased serotonergic neurotransmission in the brain may be an important deficit that leads to aggressive behavior (Edwards and Kravitz, 1997, Seo et al., 2008). Thus there appears to be growing support in the medical literature for a physio-

\footnotetext{
${ }^{7}$ See Appendix A.1 for a brief review of the literature estimating the negative consequences of violence.

${ }^{8}$ See Appendix A.2 for a review of the literature estimating the relationship between temperature and suicide and the seasonality of suicides. For example, Baron and Bell (1976) show that individuals were more likely to behave aggressively towards others when ambient temperature was higher. Burke et al. (2018) estimate the causal impact of temperature on suicides in Mexico and the U.S., and provide evidence of an increase in aggression in online networks when temperature is abnormally high.
} 
logical link between temperature and violent behavior: when ambient temperature increases, serotonin levels decrease, with attendant effects on impulsive and aggressive behavior.

A few recent studies provide complementary evidence that non-economic factors are significant in explaining reduced form relationships between temperature on violence (Garg et al., 2018, Blakeslee et al., 2018). These papers focus on interpersonal conflict, using a similar empirical strategy to ours, and both conclude (in very different settings) that the response of violent crime to temperature has a strong non-economic component. This work complements our focus on understanding the mechanisms behind intergroup conflict.

\section{Theoretical Framework}

To understand how non-economic physiological and psychological factors might complement the standard way in which economists have understood the logic of violence, we develop a simple model of violence that builds on the framework in Chassang and Padró-i-Miquel (2010) and incorporates a new mechanism affecting how high temperature can lead to violence. In the model, two sides, $i \in \mathcal{I}=\{1,2\}$, decide whether or not to engage in costly violence and redistribution when bargaining fails. The players cannot commit to not engage in conflict for an infinite number of periods, where time is indexed by $t$. On the production side, each side combines $l$ units of labor, which we normalize to $l=1$, with time-varying technology $\theta_{t}$.

The sides can engage in two possible actions, namely being violent or peaceful, $a \in \mathcal{A}=$ $\{V, P\}$, which they choose simultaneously. Both groups want to maximize their economic output at the end of the game. If one player attacks first, then it has a first strike advantage and captures all of the opponent's output with probability $p>0.5$. An attack costs both the aggressor and defender a fraction $c \in(0,1]$ of output. If both agents choose to attack simultaneously, they each win with probability 0.5. Additionally, we assume there is common knowledge of a non-rival psychological consumption value of violence, which is a function of temperature $\tau$, i.e., $\gamma_{t}=\gamma_{t}(\tau)$ with $\frac{\partial \gamma_{t}(\tau)}{\partial \tau}>0$, and $\gamma_{t}(\tau) \in \mathbb{R}$. If $\gamma_{t}(\tau)>0$ then the player gains positive utility from engaging in violence. In terms of notation, we omit the argument, $\tau$, in setting up the model, but return to it when discussing its role in explaining violence through different channels.

We consider a dynamic model where the two groups interact in every period $t$. There is at most one round of fighting, and the winning group reaps the benefits of its prize into the future. If there is no attack in the current period, then each agent expects a peaceful continuation value $V^{P}$, which is the discounted $(\delta)$ per capita utility of expected future consumption from the player's initial assets and which captures expectations of future values 
of all parameters. Similarly, if one side wins, then they have a continuation value of winning $V^{V}$, which is the per capita expected utility from consumption of both their initial assets and the assets that they capture from their opponent through violence.

The condition for peace can be written as:

$$
\underbrace{\theta_{t}+\delta V^{P}}_{\text {value of peace }}>\underbrace{p\left(2 \theta_{t}(1-c)+\delta V^{V}\right)+\gamma_{t}}_{\text {value of violence }}
$$

In terms of interpretation, a player finds it privately beneficial to choose peace if the per capita value of consuming all output with initial assets plus discounted expected utility under peace $\delta V^{P}$ (left hand side) exceeds the expected utility of consumption from both the player's original assets and captured assets, less expenditures on the conflict, plus the expected continuation value $p \delta V^{V}$ and the psychological consumption value of violence, $\gamma_{t}$ (right hand side).

Rearranging (1), the condition for peace becomes:

$$
\theta_{t}(1-2 p(1-c))-\gamma_{t}>\delta\left[p V^{V}-V^{P}\right]
$$

where the left side of the inequality is the marginal value of peace in the current period weighed against the discounted marginal expected utility from attacking (on the right side).

In considering the mechanism, the economics literature on conflict has focused on the impact of temperature on $\theta_{t}$ in explaining violence. The left hand side of $(2)$ shows that if economic conditions are sufficiently bad (i.e., $\theta_{t}$ is sufficiently close to zero), and ignoring psychological factors for the moment, conflict will occur. For example, a drought has a contemporaneous effect on productivity, which reduces the current opportunity cost of conflict more than it alters the continuation value of peace (note that $\theta_{t}$ does not feature in the right hand side).

Here we highlight the importance of the novel term capturing the non-rival psychological consumption value of violence, $\gamma_{t}$. If climatic conditions influence $\gamma_{t}$ by increasing the utility (or decreasing the psychological cost) of acting violently, i.e., $\frac{\partial \gamma_{t}(\tau)}{\partial \tau}>0$, then these changes may increase the likelihood that (2) does not hold and violence occurs. ${ }^{9}$ Focusing on levels,

\footnotetext{
${ }^{9}$ An alternative would be to introduce a physiological mechanism discussed in the literature on cognition. A number of studies have reported the importance of environmental factors, such as heat, on cognitive performance (Mackworth 1946, Fine and Kobrick 1978). Fine and Kobrick (1978) found that heat has significant effects on individuals' ability to perform complex cognitive tasks involved in artillery fire and in which they were trained. In the above model, we can think of this effect as an additive error term, $\epsilon$, whose variance increases with temperature, in which the players simply err in making their fighting decision, a decision they might not make at lower temperatures.
} 
if both sides have a general distaste for violence $\left(\gamma_{t}(\tau)<0\right)$, then there will be less conflict than would be predicted by economic factors alone. Yet even in this case, if extreme climatic conditions such as high temperatures decrease this psychological cost of engaging in violence, $\frac{\partial \gamma_{t}(\tau)}{\partial \tau}>0$, the likelihood of violence would increase with temperature.

\section{Empirical Framework}

\subsection{Data and descriptive statistics}

We collected monthly information on reported homicides and suicides at the municipality level from Mexico's Bureau of Statistics (INEGI) for the period between January 1990 and December 2010. ${ }^{10}$ This data corresponds to the universe of homicides and suicides officially reported. We split this time frame into a "pre-war" period between January of 1990 and December of 2006, and a "war" period between January of 2007 and December of 2010 because drug-related killings (henceforth DTO killings) are only available for the latter period. In the pre-war period there were 218,970 homicides and 55,206 suicides, with a monthly per municipality average (standard deviation) of 0.44 (2.49) and 0.11 (0.77), respectively. Homicides in this period include both non-DTO-related episodes and DTO killings.

We use the total number of deaths per 100,000 inhabitants in a municipality as the dependent variable, as is standard in the literature (see Hsiang et al. 2013). A municipality in Mexico is similar to a city in the United States. Figure 2 shows the time series and cross sectional variation for DTO killings and homicides for all municipalities. Table 1 presents descriptive statistics for these variables in the two periods of interest. We observe an average of 0.98 homicides and 0.21 suicides per 100,000 inhabitants per municipality-month in the pre-war period, and an average of 0.83 homicides and 0.26 suicides between years 2007 and 2010. The variation in these variables is substantial, as shown by the within standard deviations of 5.23 and 1.93 for homicides and suicides respectively. At the state level, some have as many as 6.2 homicides per 100,000 inhabitants - an extremely high homicide rate. ${ }^{11}$

\footnotetext{
${ }^{10}$ This section discusses the main variables to be used in the empirical analysis. Additional data, and the corresponding descriptive statistics, can be found in Appendix B.

${ }^{11}$ Monthly rate of 6.2 homicides in our dataset implies a rate of 74.4 homicides per 100,000 per year. This is an extremely high homicide rate. To put this in perspective, the most violent country in the world in 2012 (Honduras) had a rate of 90.4 homicides per 100,000 inhabitants, and the second most violent (Venezuela) had a rate of 53.7. Figure A.1 also compare rates of these types of violence to the US. Homicide rates in Mexico were twice as high in Mexico compared to the US in 2006 and have been rising ever since. Suicide rates, however, are substantially higher in the US. Finally, and not surprisingly, organized crime killings are far higher in Mexico, a difference that has again been increasing since 2006.
} 
DTO killings were compiled by a committee with representatives from all ministries of the National Council of Public Security in Mexico. The committee met weekly to classify each homicide as drug-related or not. A drug-related homicide was defined as one civilian killing another one with at least one involved in drug trade. The data is available from December 2006 to December 2010 at the municipality level. There were a total of 34,436 DTO killings between 2007 and 2010, with an average (standard deviation) of 0.29 (3.94) killings per municipality-month. The variation in this variable is striking, with roughly $20 \%$ of state-months having zero killings and some having as many as $452 .{ }^{12}$ Panel B in Table 1 presents descriptive statistics for this variable. DTO killings rates are roughly half the size of homicides rate during this period, and the distribution is more skewed.

Figure 2 shows time averages (weighted by population) for DTO killings (2007-2010) and homicides (1990-2006) in all municipalities in Mexico. Homicides seem to be decreasing during this time period, something analyzed in more detail by Escalante (2011). ${ }^{13}$

Finally, we construct monthly temperature and precipitation for each municipality-month using data from Willmott and Matsuura (2014). This is a gridded dataset with monthly information for cells of size 0.5 degrees. ${ }^{14}$ In order to transform this gridded dataset into a municipality-level dataset, we take the average of temperature and the sum of precipitation for all pixels inside the polygons that represent Mexican municipalities. Municipalities during our sample period have an average temperature of 20 degrees celsius, with a standard deviation of 5.0 degrees celsius. However, after removing municipality, year, and month fixed effects, following our econometric specification (below), the standard deviation of this variable at the municipality-month level is approximately 2.8 degrees celsius. Figure A.4 presents the distribution of temperature by period.

\footnotetext{
${ }^{12}$ Our results are robust to excluding states with a large upward trend in DTO killings, i.e. Baja California, Chihuahua, Durango, Guerrero, Sinaloa, and Tamaulipas. Results are also robust to including state specific trends, as discussed below.

${ }^{13}$ Dube and Ponce (2013) study violence in Mexico before 2006. These authors find that an expiration that relaxed the permissiveness of gun sales caused an increase of roughly 239 deaths annually in municipalities close to the relevant state borders.

14 "Gridded weather datasets use interpolation across space and time to combine available weather station data into a balanced panel of observations on a fixed spatial scale or grid. This approach deals with the problem of missing observations at a given station or missing data because a station does/did not exist at a particular location. (...) Each "grid" approximates a weather measure for the spatial unit by interpolating the daily station data while accounting for elevation, wind direction, rain shadows, and many other factors.", (Auffhammer et al., 2013).
} 


\subsection{Econometric strategy}

To estimate a causal link between temperature and our dependent variables of interest, we follow Deschenes and Greenstone (2007), and the preferred method employed by Hsiang et al. (2013) (see Dell et al. 2014 for a review). Accordingly, we control for unobservable time-invariant factors at the municipality level that could be correlated with both average temperatures and violence, unobserved shocks common to all municipalities within in a state in a given year, and average seasonal patterns in both temperature and violence. Specifically, in our preferred specification we estimate the following regression:

$$
y_{n s m t}=\beta \operatorname{Temp}_{n s m t}+\delta \operatorname{Precip}_{n s m t}+\xi_{m}+\lambda_{t}+\zeta_{n}+\varepsilon_{n s m t}
$$

where $y_{n s m t}$ is the number of DTO killings, homicides, or suicides per 100,000 inhabitants in municipality $n$, state $s$, month $m$, and year $t ; \xi_{m}$ and $\lambda_{t}$ are full sets of month and year fixed effects; $\zeta_{n}$ is a full set of municipality fixed effects, respectively; Temp ${ }_{n s m t}$ is average temperature, measured in degrees celsius; Precip $_{n s m t}$ is total precipitation, measured in thousands of millimeters; and $\varepsilon_{n s m t}$ is an error term clustered at the state level. In robustness tests, we also estimate equation (3) adding state-specific linear time trends (to account for differential state-level trends in, for instance, policies to fight violence), or replacing the month-of-year fixed effects $\xi_{m}$ with state-by-month-of-year fixed effects $\xi_{s m}$-to account for state specific seasonality in violence and temperature; there is some evidence, for instance, for seasonality in suicides in particular (Ajdacic-Gross et al., 2010). Our main coefficients of interest are $\beta$ and $\delta$, which are identified through natural exogenous fluctuations in weather conditions, conditional on location and time effects. After demonstrating that our results are robust across specifications, we report results from (3) for most of the analyses.

We also present temperature response functions using the number of days in a set of bins and estimates of the effect of leads and lags of temperature on violence. The latter exercise is important for a number of reasons. First, there may be temporal displacement: it may be the case that an event that would have occurred in the future anyway is triggered earlier by extreme climatic conditions. With full displacement, the contemporaneous and lagged effects would be of similar magnitude but opposite in sign, and there would be no overall effect of climate on violence. Even with partial displacement, a sole focus on contemporaneous impacts could overstate the total effect of a change in temperature.

Lags can also be useful in identifying delayed or persistent effects. For example, a negative temperature shock during the growing season in an agricultural based economy may increase violence during the harvest season when income for the farming season is realized (a delayed effect), or a weather shock could trigger a conflict that persists for multiple periods. 
Finally, the temporal pattern of response to temperature shocks could also shed light on the mechanism underpinning the response. Given that we are using monthly data, certain income effects (such as the agricultural income story just told) might be expected to show up with a few-month lag. Physiological effects, on the other hand, would be expected to show up contemporaneously, given the immediacy of the body's thermoregulatory response.

To explore these temporal dynamics, we estimate the following regression:

$$
y_{n s m t}=\sum_{k=t-6}^{k=t+6} \beta_{k} \operatorname{Temp}_{n s m k}+\sum_{k=t-6}^{k=t+6} \delta_{k} \operatorname{Precip}_{n s m k}+\xi_{m}+\lambda_{t}+\zeta_{n}+\varepsilon_{n s m t}
$$

where all variables are defined as before, and we include six monthly leads and six lags of temperature. Our interest lies in the parameters $\beta_{k}$ and $\delta_{k}$. In particular, a violation of our identification assumption would be reflected in any of the coefficients $\left(\beta_{t+1}, \ldots, \beta_{t+6}\right)$ being statistically different from zero, i.e., future climate variation should not be correlated

with past violence. Persistent effects or displacement would translate into the coefficients $\left(\beta_{t-6}, \ldots, \beta_{t-1}\right)$ being statistically different from zero.

\section{Climate and Violence}

Figure 3 non-parametrically displays the relationship between temperature and measures of group and interpersonal violence (DTO killings and homicides, respectively), with municipality, year-, and month-fixed effects partialled out of both the dependent variables and temperature. The $x$-axis is interpreted as the average temperature in a given municipality-month, and the $y$-axis is interpreted as deviation from that municipality-month average in the corresponding measure of violence. For reference, a one standard deviation in the temperature variable within a municipality corresponds to 2.8 degrees celsius. The thick line corresponds to the non-parametric conditional mean, while the lighter color depicts the 95 percent confidence interval. These temperature response functions are clearly upward sloping for both variables, and appear roughly linear through most of the temperature support.

Table 2 presents regression results from estimating equation (3) under various sets of fixed effects. To facilitate the interpretation of these coefficients, and comparison across outcomes and studies, standardized effects are presented in square brackets, which we express as percentage change in the dependent variable per one standard deviation change in the climate variable of interest. The first three columns show results using DTO killings per 100,000 inhabitants as dependent variable, and the last three show corresponding results for homicides in the pre-2007 period. 
Several interesting patterns emerge. First, we observe a positive and significant effect of temperature on both intergroup and interpersonal violence, a result that is robust across all specifications. The magnitude of these estimates varies across columns, but is particularly large for DTO killings: in our base specification (Column 1), we find that a $1 \sigma$ increase in temperature in a given month is associated with a $28 \%$ increase in the rate of DTO killings. This result is robust to inclusion of either state-specific time trends or state-month FE. Given the large level of killings during this period - over 34,000 DTO killings over the 2007-2010 period - a $22 \%$ increase is large in both percentage and absolute terms. The roughly $5 \%$ effect for homicides is smaller in magnitude, but is also substantial given again the high homicide rate in the country over the period (285,000 total homicides during the 1990-2010 period). We find no statistically significant effect of precipitation on either intergroup or interpersonal violence, and in all specifications we can confidently reject large effects of precipitation. The effects of climate on violence in Mexico appear to occur through temperature.

Why is the impact of temperature shocks on violence larger for organized groups? ${ }^{15}$ Although our setting prevents us from providing a complete explanation, we believe there are at least three leading possibilities that merit further exploration. First, DTO operatives on the ground might be more equipped to engage in violent behavior (i.e., they are often armed) and as a result temperature shocks might have a larger impact on them. Second, DTO individuals might simply be more violent by nature, either because they were trained by the organization with that purpose or because they were selected from the population in part due to an underlying tendency to violence. Third, social interactions within or across groups could exacerbate the effects of temperature. Examples of these potential "social multipliers" are peer effects within groups and retaliation across groups.

Anticipating our more formal treatment of treatment-effect heterogeneity below, in Figure A.2 we explore whether there are apparent spatial patterns in the responsiveness of DTO killings or homicides to temperature. We estimate state-specific responses of violence to temperature, and display these in the figure as the ratio of the state-specific estimate to the pooled country-wide estimate reported in Columns 1 or 4 of Table 2 - i.e. $\frac{\widehat{\beta}_{s, y}}{\widehat{\beta}_{y}}$. Although there is some apparent variation in estimated effects across states, results are remarkably homogeneous: point estimates are positive in all states for DTO killings and positive in all but one state for homicides, the ratio of state-specific estimates to pooled estimates is near unity for most states, and in the case of DTO killings, in only 4 out of 32 states do confidence intervals on state-specific estimates not contain the pooled estimate (equivalent

\footnotetext{
${ }^{15}$ Although a meta-analysis finds a larger effect of temperature on intergroup violence (Hsiang et al., 2013), the results in Table A.3 cannot reject that the temperature response is similar for homicides and DTO killings. However, this result needs to be interpreted with caution because it only uses data for the 2007-2010 period.
} 
to $13 \%$ of states, only slightly higher than what sampling variability alone would predict). For homicide, there does appear to be somewhat more variation in effect sizes across states, with $38 \%$ of state-specific confidence intervals not containing the country-wide estimate (8 estimates are significantly larger than the pooled estimate, 4 are smaller). Below we explore more extensively whether economic factors can explain this heterogeneity.

Finally, as shown in Figure 4, our benchmark estimates of how intergroup and interpersonal violence respond to temperature in Mexico are remarkably consistent with other reported temperature-conflict estimates from the literature (none of which were from Mexico). Figure 4 plots the distribution of standardized coefficients from an earlier meta-analysis (Hsiang et al., 2013), showing in the bottom two panels either the 24 studies from Hsiang et al. (2013) that examined intergroup conflict or the 12 studies that examined interpersonal conflict. The estimated effects for DTO killings and homicides from Mexico lie within the expected distributions for intergroup and interpersonal conflict, respectively. In particular, in the existing literature a one standard deviation rise in temperature increases interpersonal violence by $4 \%$ and intergroup conflict by $14 \%$, quite close to the $4.5 \%$ and $22.8 \%$ we estimate for homicides and DTO killings, respectively, in Mexico.

\section{Economic Factors}

\subsection{Other DTO criminal activities}

Can economic factors explain the strong and robust relationship between temperature and violence in Mexico? In the absence of a way to experimentally manipulate the income of drugtrafficking organizations, we approach the problem indirectly. First, we study whether other (plausibly) economically-motivated DTO criminal activities also respond to temperature. Besides killings, drug trafficking organizations are also known for other criminal activities such as kidnappings, extortion, and car thefts. These crimes appear to have a clear economic motivation, and so if economic factors such as income are what is mediating how DTO violence responds to temperature, a similar temperature response might be evident in these similarly economically-motivated activities.

We assembled administrative data on the monthly occurrence of kidnappings, extortion, and car thefts during the period between January of 2007 and December of 2010. Unfortunately these data is not available at the municipality level but at the state level instead. Table 3 present the estimates of interest, and include our main results on DTO killings and homicides for comparison. Strikingly, we do not observe any significant relationship between 
temperature and these other criminal activities. In fact, estimated coefficients have a negative sign in the case extortions and kidnappings, although are not statistically significant, and the effect on car thefts is fairly small and not statistically significant. Temperatures appear to increase violent crime but not these other criminal activities.

\subsection{Income, unemployment, and inequality}

The first approach suggests that the observed relationship between temperature and violence cannot be explained by an economic mechanism. To further substantiate the argument that psychological factors drive the results, our second approach is to look directly at whether municipality-level income variables mediate the temperature-violence relationship. To do this, we augment equation (3) and include an interaction term between temperature and various measures of income or income inequality at the municipality level. In particular, we examine interactions with municipality-level income and with the municipality-level Gini coefficient.

Results are shown in Table 4. We find little evidence that these municipality-level measures of income mediate the temperature-violence relationship. For the per-capita income measure, the interaction has the expected sign for DTO killings, but is statistically insignificant and the coefficient is small: a one standard deviation increase in log GDP per capita, which we think of as being a fairly large increase in income, attenuates the effect of temperature on DTO killings by 13 percent $(-0.008 / 0.063 \approx 0.13)$. The interaction in the homicide regression is also statistically insignificant, and is of the opposite sign than expected.

Another economic measures is economic inequality, measured here with time-invariant municipality-level Gini coefficients (constructed by Jensen and Rosas 2007). Income inequality has been argued in the literature to be an important driver of violence and conflict in different settings. But as shown in the table, it does not appear to substantially affect how either intergroup or interpersonal violence respond to temperature in Mexico. In the case of DTO killings, a one standard deviation in inequality decreases the effect of temperature on violence by roughly 12 percent, but it is not statistically significant.

Finally, we explore the mediating influence of two other variables that are typically correlated with income: the adoption of air conditioning (typically positively correlated with income), and municipality-level average temperature (negatively correlated with income across countries as well as across Mexican states). ${ }^{16}$ Air conditioning could be viewed as an

\footnotetext{
${ }^{16}$ Davis and Gertler (2015) find a positive relationship between household income and air conditioner adoption within warm areas of Mexico; adoption in cooler areas is close to zero.
} 
income-related adaptation, and as such could represent an alternative pathway through which higher incomes could break the link between temperature and violence. ${ }^{17}$ The "mediating" effect of higher average temperatures on the response of violence to temperature deviations is perhaps more subtle. One the one hand, states with higher average temperatures might be more adapted to hot temperatures, and thus less effected by additional increases in temperature. On the other hand, if the underlying temperature response is non-linear (as in agricultural productivity), then additional heat exposure on top of an already high mean should induce a more negative response.

Results of including air conditioning penetration or average temperature as interaction variables are show in columns 3 and 7 of Table 4 . The evidence on whether either variable mitigates the temperature-violence response function is inconclusive. The estimates are not statistically significant, but we can bound the potential for mitigation: there is at most a $10-12 \%$ reduction in the effect as a response to an increase of one standard deviation in AC penetration. Thus we find little additional evidence of income-induced adaptation (at least through the AC channel), nor strong evidence that hotter average temperatures reduce impacts (through adaptation) or worsen them (through non-linearities).

\subsection{Quasi-experimental variation in monetary transfers}

Our third approach to studying the role of economic factors is to exploit the roll-out of a large-scale conditional cash transfer program, PROGRESA, which induced quasi-experimental variation in income across much of Mexico during our study period. PRogresa is a very large program, with a budget of approximately 133 million USD in 1997 (roughly 0.03\% of GDP), which has since expanded to almost 5 billion USD in 2010 (roughly $0.5 \%$ of GDP). In terms of the roll-out of the program, the government originally chose 320 treatment and 185 control rural villages. The former villages were located in 110 municipalities, were chosen at random, and received the first treatment in August 1998; the latter villages received the treatment two years later (Skoufias et al., 2001).

After 2002, municipalities treated first were presumably more vulnerable. This is because the government used a variety of methods to identify eligible households, including estimates of household income and self-selection methods with ex-post verification of eligibility (more details in Levy 2006). Nevertheless, because our estimation strategy employs local fixed effects, exploits the timing in the implementation of the program using monthly variation,

\footnotetext{
${ }^{17}$ Barreca et al. (2016) find that the effect of higher temperature on mortality declined dramatically over the course of the 21st century in the United States. They show that the diffusion of residential air conditioning explains nearly all of this decline.
} 
and temperature shocks are unlikely to be correlated with program roll-out, this feature of the program should not bias our results. ${ }^{18}$

In terms of the data, we observe bimonthly transfers to every municipality during the period between January 1998 and December of 2009 from administrative sources. Importantly, cash transfers in this program targeted women with children, and so we cannot be certain the extent of income variation that the program induced among the population likely to participate in DTO related activities (young men). ${ }^{19}$ Nevertheless, we augment our main regression equation by including the logarithm of PROGRESA transfers as an additional independent variable, and an interaction term between this variable and temperature.

Results from this exercise are presented in Table 5. First, transfers alone seem to decrease the rate of DTO killings, although the effect is relatively modest and not statistically significant: an increase of 10 percent in transfers decreases killings by 0.1 percent. The effect is smaller in the case of homicides and not statistically significant. Regarding the interaction term, the coefficient is also negative and marginally significant in the case of DTO killings, which suggests transfers also modestly decrease the local sensitivity of violence to temperature, but it is again a fairly precise estimated zero in the case of homicides.

In Figure A.5 we also incorporated an interaction term between leads and lags of PROGRESA transfers and temperature and we reach the same conclusion: transfers modestly decrease DTO killings, but only contemporaneously, these have no effect on homicides, and the interaction term is marginally significant and negative only for the case of DTO killings. Overall, it seems that even large monetary transfers to poor households in a very high-profile anti-poverty social assistance program can only slightly reduce levels of intergroup violence and have no effect in the case of interpersonal violence - again subject to the caveat that we cannot be sure how much of this income reached those individuals likely to participate in DTO activities.

\subsection{Harvest and growing season effects}

Our final approach to exploring the role of economic factors is to study whether temperature shocks during economically critical periods have a greater impact on violence compared to shocks at other times in the year. In particular, as a substantial portion of the Mexican

\footnotetext{
${ }^{18}$ In fact, the results in this section are virtually identical in the ProGresA phase (1998-2001, coef. -0.003, $p$-value 0.67 ) and the OpORTunidades period (2002-2006, coef. -0.003, $p$-value 0.38 ).

${ }^{19}$ This is one reason our results likely diverge from Fetzer et al. (2019), who shows that the relationship between monsoon shocks and insurgent conflict is largely eliminated in India after the introduction of a public employment program (NREGA) that guaranteed wage labor to everyone.
} 
labor force continues to earn their living in agriculture (roughly 15\%), and as agricultural income has been one of the most salient variables emphasized in the literature as a potential mediating factor between climate and conflict, we examine the effect of temperature during the growing and harvest seasons relative to during non-agricultural seasons. More precisely, we construct an indicator variable that takes the value of one for the months of April to September, which is considered the rainy season for the majority of Mexico and includes both the canicula and pre-canicula period. ${ }^{20}$ The harvest season indicator variable, on the other hand, takes on a value of one during the months of October to December.

We perform two different analyses. In the first one, we simply augment our main regression equation with an interaction between temperature and the indicator variable for the growing season. Our expectation is that this interaction will be positive if agricultural income is a mediating factor and if agricultural incomes (e.g., wages) respond rapidly to changes in temperature. Given that these income shocks might occur with some lag, with hot temperatures during the growing season only showing up as negative incomes shocks after crops have been harvested a few months later, our second approach studies how violence in the harvest season reacts to temperature shocks during the growing season.

Results are shown in Table 6. We find that temperature shocks during the growing season appear to reduce DTO killings somewhat, the opposite of what the agricultural income story would suggest, with the coefficient on the interaction not significant at conventional levels. For the test on whether growing season shocks affect harvest season violence, point estimates for both DTO killings and homicides are positive, but standard errors are too large to be able to rule out either zero effect or large positive or negative effects. Finally, we also include interaction terms with the percentage of households living in rural areas and the percentage of workers in the agricultural sector, and find similar results. Taken as a whole, these results provide little evidence that agricultural income is the critical mediating factor.

\section{The role of non-economic factors in violence}

Results from section 6 suggest that economic factors have only limited power to explain the observed effect between temperature and both intergroup and interpersonal violence in Mexico or to mitigate what we argue is at least in part a psychological channel. We find that changes in temperature do not affect other economically motivated non-violent crimes, that other measures of economic conditions such as municipality-level income do not

\footnotetext{
${ }^{20}$ Canicula is a mid-summer drought period in Mexico. Both the growing and harvest season were specified following Skoufias (2012), who examines the effect of weather shocks on household welfare in Mexico.
} 
predict the temperature response, that random variation in governmental income assistance have only a modest dampening effect, and that growing season temperature shocks are not differentially harmful. None of these results is definitive on its own, but together they suggest that economic factors are unlikely to be the driving force in explaining the large response of violence to temperature in this setting.

How can we directly show that psychological factors instead at least partially explain the link between temperature and violence? Because inducing experimental variation in these psychological factors is logistically challenging (and, arguably, ethically undesirable), our approach to understanding their potential role is again indirect. In particular, our basic approach is a "pattern-matching" exercise, where we study whether the response pattern of group violence to temperature matches the response pattern of another type of violence that is almost certainly lined to psychological factors - intrapersonal violence, i.e., suicide.

Suicide has long been understood to have a substantial psychological component. For instance, the medical literature tells us that psychiatric disorders are reported present in at least $90 \%$ of suicides (Mann et al., 2005), propensity toward suicidal behavior is strongly associated with genetic inheritance (Brent and Melhem, 2008), and randomized controlled trials suggest that suicide risk can be substantially shaped both by medications and by psychotherapy (Mann et al., 2005). Researchers have also long recognized the role that changes in temperature might play in shaping suicide risk, although the literature is currently inconclusive as to whether stark seasonal patterns in suicide (which characteristically peak during warm spring and summer months) are due to temperature per se or to other factors that also vary seasonally (see Appendix A.2 for a review of this literature).

Using an identical econometric strategy to that used for DTO killings and homicides above, and building on recent work in Burke et al. (2018), we begin by showing that suicides in Mexico also respond strongly to deviations from average temperature. The non-parametric relationship between suicide and temperature is shown in Figure 5, and corresponding regression results are given in the first column of Table 7. As with DTO killings and homicides, the temperature-suicide relationship appears strongly linear, with an estimated standardized effect of a $7 \%$ increase in suicide per $\sigma$ increase in temperature (Table 7 ). This estimate falls between the estimated effects for DTO killings and homicides. As with these latter outcomes, the suicide response also appears fairly homogenous across states, with positive estimates in all but 2 states (see Figure A.2-C).

As with DTO killings and homicide, we then explore whether the temperature-suicide relationship is mediated by economic factors. This is, in essence, a further gut check on whether suicide is a fair "benchmark" for an outcome that we presume is mainly non- 
economic in nature. Results from including interactions with income, inequality, Progresa transfers, and growing season temperature are shown in the remaining columns of Table 7. Most coefficients on interactions are small and statistically insignificant, and the two interactions with statistical significance have signs that go in the opposite direction than what the typical income story would suggest: higher average incomes appear to slightly worsen the impact of hot temperatures, and hotter-than-average growing seasons appear to reduce the impact of temperature.

As a final pattern matching exercise, we study the temporal pattern of how intergroup, interpersonal, and intrapersonal violence respond to temperature, using the leads/lags approach described in equation 4. As discussed above, studying the temporal pattern of responses can help shed additional light on mechanisms, since income effects might be expected to show up with some lag in monthly data but physiological effects should show up immediately. Studying lags also allows us to understand whether contemporaneous effects are simply "displacement", causing violence to occur earlier than it would have otherwise, but not changing the overall level of violence. Studying leads offers a simple placebo test, as idiosyncratic variation in future temperature should not affect current violence.

Results from estimating equation 4 on all three outcomes are shown in Figure 6, with point estimates and confidence intervals for contemporaneous effects, 6 lags, and 6 leads plotted for each outcome (for instance, a value of "- 1 " on the x-axis corresponds to the effect of temperature in month $t-1$ on violence in month $t$ ). Although estimates are again more imprecise for DTO killings due to the smaller sample size, a number of common patterns are apparent. First, statistically significant effects occur only in contemporaneous periods for all three outcomes. That is, the most robust predictor of violence in a given month is temperature in that month, suggesting that the primary effects of temperature are immediate. We interpret this as additional evidence in favor of physiological mechanisms, since these would be expected to respond immediately to temperature change.

We also find evidence of some displacement, with lagged coefficients for both homicide and suicides negative and (for suicides) significant. In absolute value, these coefficients are about $1 / 3$ rd the size of the contemporaneous effects, suggesting that roughly one-third of the temperature-induced increase in homicides and suicides were events that were likely to have occurred anyway. Interestingly, we do not see a similar pattern for DTO killings, although generally larger standard errors on the DTO estimates limit our ability to say anything very precise. Finally, results on the leads (our placebo test) are largely reassuring, with most point estimates of the 6 leads near zero and none statistically significant. There are thus two imperfect but consistent pieces of evidence that non-economic factors could explain some of the temperature-violence relationship. The first is that a known psychologically-dependent 
outcome, suicide, responds in a strikingly similarly way to changes in temperature. We view the extent of this similarity as unlikely if suicide did not share some underlying commonalities in terms of mechanism with these other forms of violence. The second is that the effect of temperature on all types of violence that we measure is immediate - i.e., that it occurs in the same month as the temperature shock - which is inconsistent with the most obvious incomerelated stories in which temperature reduces agricultural output, given that the period in which crops are sensitive to temperature is temporally disjoint from the period in which harvest income is realized. Again, each of these pieces of evidence on their own might not be convincing, but together they suggest a substantial role for non-economic factors in explaining how both intergroup and interpersonal violence in Mexico respond to changes in temperature.

\section{Conclusion}

Using municipality-by-month variation in temperature, we find significant contemporaneous effects of temperature on DTO killings, homicides, and suicides in Mexico. Estimated effects are economically meaningful for each outcome, and imply that temperature can induce large additional increase in violence on top of already high baseline levels of both DTO killings and homicides. This is the first study to our knowledge to find such a similar relationship across a spectrum of violence outcomes in a single setting, and our estimated effects are surprisingly consistent with existing estimates in the literature from other contexts.

Using a variety of approaches and data, we assess whether non-economic factors are contributing to the results. A constellation of evidence, including the limited influence of a cash transfer program as well as comparison with economically-motivated non-violent DTO crimes, indicate that economic factors can at best only partially explain the observed relationship between temperature and violence or mitigate what we argue is a psychological channel. We present two pieces of of more direct evidence that suggest a role for noneconomic factors in explaining the temperature-violence link for group- and interpersonal violence: the substantial similarity between how these outcomes respond to temperature and how suicide responds to temperature, and the immediacy of the response of these variables to changes in temperature.

We draw two tentative policy implications from our findings. The first is that, at least in this particular setting, standard economic interventions might not be an effective tool for shaping how violence responds to changes in climate. Second, our results are equally pessimistic on the role for adaptation in shaping this response, with neither higher average 
income levels nor specific interventions that alter how individuals experience climate (i.e., air conditioning) appearing to affect how violence responds to temperature. More speculatively, reducing future temperature increases through emissions mitigation, rather than trying to induce adaptation through policy intervention (or hoping that it will occur on its own), thus unfortunately may be the most fruitful strategy in this setting for limiting the violent consequences of future climate change.

\section{References}

Abounoori, E. and McCloughan, P. (2003). A simple way to calculate the gini coefficient for grouped as well as ungrouped data. Applied Economics Letters.

Aizer, A. (2010). The gender wage gap and domestic violence. American Economic Review, 100(4):1847-1859.

Ajdacic-Gross, V., Bopp, M., Ring, M., Gutzwiller, F., and Rossler, W. (2010). Seasonality in suicide: A review and search of new concepts for explaining the heterogeneous phenomena. Social Science and Medicine, 71:657-666.

Ajdacic-Gross, V., Lauber, C., Sansossio, R., Bopp, M., Eich, D., Gostynski, M., Gutzwiller, F., and Rossler, W. (2007). Seasonal associations between weather conditions and suicideevidence against a classic hypothesis. American Journal of Epidemiology, 165(5):561-569.

Akbulut-Yuksel, M. (2014a). Children of war: The long-run effects of large-scale physical destruction and warfare on children. Journal of Human Resources, 49(3):634-662.

Akbulut-Yuksel, M. (2014b). War during childhood: The long-run effects of warfare on health. Journal of Health Economics, 53:117-130.

Akbulut-Yuksel, M., Khamis, M., and Yuksel, M. (2013). For better or for worse: The long-term effects of postwar reconstruction on family formation. IZA Discussion Paper No. 7239.

Akresh, R. (2012). Wars and child health: Evidence from the eritrean-ethiopian conflict. Journal of Development Economics, 99(2):330-340.

Angrist, J. D. and Kugler, A. D. (2008). Rural windfall or a new resource curse? Coca, income, and civil conflict in Colombia. The Review of Economics and Statistics, 90(2):191215.

Auffhammer, M., Hsiang, S. M., Schlenker, W., and Sobel, A. (2013). Using weather data and climate model output in economic analyses of climate change. Review of Environmental Economics and Policy, 7(2):181-198. 
Baez, J. E. (2011). Civil wars beyond their borders: The human capital and health consequences of hosting refugees. Journal of Development Economics, 96:391-408.

Barker, A., Hawton, K., Fagg, J., and Jennison, C. (1994). Seasonal and weather factors in parasuicide. British Journal of Psychiatry, 165:375-380.

Baron, R. A. and Bell, P. A. (1976). Aggression and heat: The influence of ambiente temperature, negative affect, and a cooling drink on physical aggression. Journal of Personality and Social Psychology, 33(3):245-255.

Barreca, A., Clay, K., Deschenes, O., Greenstone, M., and Shapiro, J. S. (2016). Adapting to climate change: The remarkable decline in the us temperature-mortality relationship over the twentieth century. Journal of Political Economy, 124(1):105-159.

Becker, G. (1968). Crime and punishment: An economic approach. Journal of Political Economy, 76(2):169-217.

Benzinger, T. (1970). Peripheral cold reception and central warm reception, sensory mechanisms of behavioural and automatic thermostasis. In J.F. Hardy, A. G. and Stolwijk, J., editors, Physiological and Behavioural Temperature Regulation. Springfield, IL: Thomas.

Berman, E., Shapiro, J. N., and Felter, J. H. (2011). Can hearts and minds be bought? The economics of counterinsurgency in Iraq. Journal of Political Economy, 119(4):766-819.

Besley, T. and Persson, T. (2011). The logic of political violence. Quarterly Journal of Economics, 126(3):1411-1445.

Blakeslee, D., Chaurey, R., Fishman, R., Malghan, D., and Malik, S. (2018). In the heat of the moment: Economic and non-economic drivers of the weather-crime relationship. Working Paper.

Blattman, C. and Annan, J. (2010). The consequences of child soldiering. Review of Economics and Statistics, 92(4):882.

Blattman, C., Jamison, J. C., and Sheridan, M. (2017). Reducing crime and violence: experimental evidence from cognitive behavioral therapy in Liberia. American Economic Review, 107(4):1165-1206.

Blattman, C. and Miguel, E. (2010). Civil war. Journal of Economic Literature, 48(1):3-57.

Bowlus, A. and Seitz, S. (2006). Domestic violence, employment and divorce. International Economic Review, 47(4):1113-1149.

Bozzoli, C., Bruck, T., and Wald, N. (2012). Self-employment and conflict in colombia. Journal of Conflict Resolution, 57(1):117-142.

Brent, D. A. and Melhem, N. (2008). Familial transmission of suicidal behavior. Psychiatric Clinics of North America, 31(2):157-177. 
Brown, R. (2018). The mexican drug war and early-life health: The impact of violent crime on birth outcomes. Demography, 55:319-340.

Buckley, B. M., Anchukaitis, K. J., Penny, D., Fletcher, R., Cook, E. R., Sano, M., Wichienkeeo, A., Minh, T. T., Hong, T. M., et al. (2010). Climate as a contributing factor in the demise of angkor, cambodia. Proceedings of the National Academy of Sciences, 107(15):6748-6752.

Bundervoet, T., Verwimp, P., and Akresh, R. (2009). Health and civil war in rural burundi. Journal of Human Resources.

Burke, M., González, F., Baylis, P., Heft-Neal, S., Baysan, C., Basu, S., and Hsiang, S. (2018). Higher temperatures increase suicide rates in the United States and Mexico. Nature Climate Change, 8:723-729.

Burke, M., Hsiang, S., and Miguel, E. (2015). Climate and conflict. Annual Review of Economics, 7:577-617.

Burke, M. B., Miguel, E., Satyanath, S., Dykema, J. A., and Lobell, D. B. (2009). Warming increases the risk of civil war in africa. Proceedings of the national Academy of sciences, 106(49):20670-20674.

Calderón, G., Díaz-Cayeros, A., Magaloni, B., and Robles, G. (2015). The beheading of criminal organizations and the dynamics of violence in Mexico. Journal of Conflict Resolution, 59(8):1455-1485.

Camacho, A. and Rodriguez, C. (2012). Firm exit and armed conflict in colombia. Journal of Conflict Resolution, 57(1):89-116.

Card, D. and Dahl, G. B. (2009). Family violence and football: The effect of unexpected emotional cues on violent behavior. Quarterly Journal of Economics, 126(1):103-143.

Castillo, J. C., Mejia, D., and Restrepo, P. (2018). Scarcity without leviathan: The violent effects of cocaine supply shortages in the Mexican Drug War. Review of Economics and Statistics.

Cave, D. (2011). Better lives for mexicans cut allure of going north. The New York Times.

Chaidez, L. (2014). More police funding, more violence? Regression Discontinuity Evidence. Working Paper.

Chamarbagwala, R. and Moran, H. E. (2011). The human capital consequences of civil war: Evidence from guatemala. Journal of Development Economics, 94(1).

Chassang, S. and Padró-i-Miquel, G. (2010). Economic shocks and civil war. Quarterly Journal of Political Science, 4:211-228.

Chimeli, A. and Soares, R. (2017). The use of violence in illegal markets: Evidence from mahogany trade in the Brazilian Amazon. American Economic Journal: Applied Economics, $9(4): 30-57$. 
Chiu, L. P. W. (1988). Do weather, day of the week, and address affect the rate of attempted suicide in hong kong? Social Psychiatry and Psychiatric Epidemiology.

Christodoulou, C., Douzenis, A., Papadopoulos, F. C., Papadopoulo, A., Bouras, G., Gournellis, R., and Lykouras, L. (2012). Suicide and seasonality. Acta Psychiatrica Scandinavica, 125:127-146.

Collier, P. and Hoeffler, A. (1998). On economic causes of civil war. Oxford economic papers, 50(4):563-573.

Cooper, K. (2002). Molecular biology of thermoregulation: Some historical perspectives on thermoregulation. Journal of Applied Physiology, 92(4):1717-1724.

Coscia, M. and Rios, V. (2012). Knowing where and how criminal organizations operate using web content. In 21st ACM International on Information and Knowledge Management.

Cruz Santiago, C., Cruz Santiago, C. A., Fumarulo, S., Ruggiero, P., Poscetti, G., and Dell'Olio, T. (2012). México: La guerra invisible. historias, cifras y negocios de los carteles criminales y la impunidad de las mafias mexicanas. Libera.

Davis, L. W. and Gertler, P. J. (2015). Contribution of air conditioning adoption to future energy use under global warming. Proceedings of the National Academy of Sciences, 112(19):5962-5967.

Deisenhammer, E. A. (2003). Weather and suicide: the present state of knowledge on the association of metereological factors with suicidal behaviour. Acta Psychiatrica Scandinavica.

Deisenhammer, E. A., Kemmler, G., and Parson, P. (2003). Association of meteorological factors with suicide. Acta Psychiatrica Scandinavica, 108:455-459.

Dell, M. (2015). Trafficking networks and the mexican drug war. American Economic Review, 105(6):1738-1779.

Dell, M., Feigenberg, B., and Teshima, K. (2019). The violent consequences of trade-induced worker displacement in Mexico. American Economic Review: Insights, 1(1):43-58.

Dell, M., Jones, B., and Olken, B. (2014). What do we learn from the weather? The new climate-economy literature. Journal of Economic Literature, 52(3):740-798.

Dell, M., Jones, B. F., and Olken, B. A. (2012). Temperature shocks and economic growth: Evidence from the last half century. American Economic Journal: Macroeconomics, $4(3): 66-95$.

Deschenes, O. and Greenstone, M. (2007). The economic impacts of climate change: Evidence from agricultural output and random fluctuations in weather. American Economic Review, 97(1):354-385.

Dixon, K. and Shulman, M. (1983). A statistical investigation into the relationship between meteorological parameters and suicide. International Journal of Biometeorology. 
Dixon, P. G., McDonald, A. N., Scheitlin, K. N., Stapleton, J. E., Allen, J. S., Carter, W. M., Holley, M. R., Inman, D. D., and Roberts, J. B. (2007). Effects of temperature variation on suicide in five u.s. counties, 1991-2001. International Journal of Biometeorology, 51:395403.

Donohue, J. J. and Levitt, S. D. (1998). Guns, violence, and the efficiency of illegal markets. American Economic Review Papers and Proceedings, 88(2):463-467.

Dube, O. and Ponce, O. D. G. (2013). Cross-border spillover: U.S. gun laws and violence in Mexico. American Political Science Review, 107(3):397-417.

Dube, O., Ponce, O. D. G., and Thom, K. (2016). From maize to haze: Agricultural shocks and the growth of the Mexican drug sector. Journal of the European Economic Association, 14(5):1181-1224.

Dube, O. and Vargas, J. F. (2013). Commodity price shocks and civil conflict: Evidence from Colombia. The Review of Economic Studies, 80(4):1384-1421.

Edwards, D. H. and Kravitz, E. A. (1997). Serotonin, social status and aggression. Current Opinion in Neurobiology, 7:812-819.

Escalante, F. (2011). Homicidios 2008-2009: la muerte tiene permiso. Nexos.

Farmer, A. and Tiefenthaler, J. (1997). An economic analysis of domestic violence. Review of Social Economy.

Fernandez, M., Ibanez, A. M., and Pena, X. (2011). Adjusting the labor supply to mitigate violent shocks: Evidence from rural colombia. Journal of Development Studies, 50(8):11351155 .

Fetzer, T. et al. (2019). Can workfare programs moderate conflict? evidence from india. Technical report.

Fine, B. and Kobrick, J. (1978). Effects of altitude and heat on complex cognitive tasks. Human Factors, 20(1):115-122.

Garg, T., McCord, G. C., and Montfort, A. (2018). Losing your cool: Psychological mechanisms in the temperature-crime relationship in Mexico. Working Paper.

Grillo, I. (2012). El Narco: Inside Mexico's Criminal Insurgency. Bloomsbury Press.

Grove, O. and Lynge, J. (1979). Suicide and attempted suicide in greenland. Acta Psychiatrica Scandinavica.

Guerrero, E. (2010). Cómo reducir la violencia en méxico. Nexos.

Guerrero, E. (2011a). La raíz de la violencia. Nexos.

Guerrero, E. (2011b). Security, drugs, and violence in mexico: A survey. 7th North American Forum, Washington D.C. 
Guerrero, E. (2012a). 2011: La dispersión de la violencia. Nexos.

Guerrero, E. (2012b). Epidemias de violencia. Nexos.

Hajat, S., Kovats, R. S., and Page, L. (2007). Relationship between daily suicide counts and temperature in england and wales. The British Journal of Psychiatry.

Hammel, H. T. (1974). A set-point in temperature regulation: Analogy or reality. Defense Technical Information Center.

Harari, M. and Ferrara, E. L. (2018). Conflict, climate, and cells: a disaggregated analysis. Review of Economics and Statistics, 100(4):594-608.

Haug, G. H., Günther, D., Peterson, L. C., Sigman, D. M., Hughen, K. A., and Aeschlimann, B. (2003). Climate and the collapse of maya civilization. Science, 299(5613):1731-1735.

Helama, S., Holopainen, J., and Partonen, T. (2013). Temperature-associated suicide mortality: contrasting roles of climatic warming and the suicide prevention program in finland. Environmental Health and Preventive Medicine.

Holopainen, J., Helama, S., and Partonen, T. (2013). Does diurnal temperature range influence seasonal suicide mortality? assessment of daily data of the helsinki metropolitan area from 1973 to 2010. International Journal of Biometeorology.

Hsiang, S. M. (2010). Temperatures and cyclones strongly associated with economic production in the Caribbean and Central America. Proceedings of the National Academy of Sciences, 107(35):15367-15372.

Hsiang, S. M., Burke, M., and Miguel, E. (2013). Quantifying the influence of climate on human conflict. Science, 341 .

Hsiang, S. M., Meng, K. C., and Cane, M. A. (2011). Civil conflicts are associated with the global climate. Nature, 476(7361):438.

Inoue, K., Nishimura, Y., Fujita, Y., Ono, Y., and Fukunaga, T. (2012). The relationship between suicide and five climate issues in a large-scale and long term study in japan. West Indian medical Journal, 61(5):532-537.

Jacob, B., Lefgren, L., and Moretti, E. (2007). The dynamics of criminal behavior: Evidence from weather shocks. Journal of Human Resources, 42(3):489-527.

Jensen, N. M. and Rosas, G. (2007). Foreign direct investment and income inequality in Mexico, 1990-2000. International Organization, 61(3):467-487.

Jessen, G., Steffensen, P., and Jensen, B. F. (1998). Seasons and meteorological factors in suicidal behaviour: Findings and methodological considerations from a danish study. Archives of Suicide Research.

Kim, Y., Kim, H., and Kim, D.-S. (2011). Association between daily environmental temperature and suicide mortality in korea (2001-2005). Psychiatry Research, 186:390-396. 
Kondylis, F. (2010). Conflict displacement and labor market outcomes in post-war bosnia and herzegovina. Journal of Development Economics, 93:235-248.

Larrick, R. P. and et al (2011). Temper, temperature, and temptation: Heat-related retaliation in baseball. Psychological Science, 22(4):423-428.

Lee, H.-C., Lin, H.-C., Tsai, S.-Y., Li, C.-Y., Chen, C.-C., and Huang, C.-C. (2006). Suicide rates and the association with climate: A population-based study. Journal of Affective Disorders, 92:221-226.

Leiner, M., Puertas, H., Caratachea, R., Avila, C., Atluru, A., Briones, D., and de Vargas, C. (2012). Children's mental health and collective violence: A binational study on the united states-mexico border. Revista Panamericana de Salud Publica, 31(5).

León, G. (2012). Civil conflict and human capital accumulation: The long-term effects of political violence in peru. Journal of Human Resources, 47(4):991-1023.

Leung, C. M., Chung, W. S. D., and So, E. P. M. (2002). Burning charcoal: An indigenous method of commiting suicide in hong kong. Journal of Clinical Psychiatry, 63(5):447-450.

Levy, S. (2006). Progress Against Poverty: Sustaining Mexico's Progresa-Oportunidades Program. Washington D.C.: Brookings Institution Press.

Likhvar, V. and Honda, Y. (2011). Relation between temperature and suicide mortality in japan in the presence of other confounding factors using time-series analysis with a semiparametric approach. Environmental Health and Preventive Medicine, 16:36-43.

Linkowski, P., Martin, F., and Maertelaer, V. D. (1992). Effect of some climatic factors on violent and non-violent suicides in belgium. Journal of Affective Disorders, 1992(25):161166.

Lovheim, H. (2012). A new three-dimensional model for emotions and monoamine neurotransmitters. Medical Hypotheses, 78(2):341-348.

Mackworth, N. (1946). Effects of heat on telegraphy operators hearing and recording morse messages. British Journal of Industrial Medicine.

Mann, J. J., Apter, A., Bertolote, J., Beautrais, A., Currier, D., Haas, A., Hegerl, U., Lonnqvist, J., Malone, K., Marusic, A., et al. (2005). Suicide prevention strategies: a systematic review. Jama, 294(16):2064-2074.

Marion, S. A., Agbayewa, M. O., and Wiggins, S. (1990). The effect of season and weather or suicide rates in the elderly in british columbia. Canadian Journal of Public Health, 90(6):418-422.

Mekjavic, I. and Eiken, O. (2006). Contribution of thermal and nonthermal factors to the regulation of body temperature in humans. Journal of Applied Physiology, 100.

Merino, J. (2011). Los operativos conjuntos y la tasa de homicidios: Una medición. Nexos. 
Miguel, E. and Roland, G. (2011). The long-run impact of bombing vietnam. Journal of Development Economics, 96:1-15.

Miguel, E., Satyanath, S., and Sergenti, E. (2004). Economic shocks and civil conflict: An instrumental variables approach. Journal of Political Economy, 112(4):725-753.

Milanovic, B. (1994). The gini-type functions: An alternative derivation. Bulleting of Economic Research.

Mills, C. A. (1934). Suicides and homicides in their relation to weather changes. The American Journal of Psychiatry.

Morrison, S., Nakamura, K., and Madden, C. (2008). Central control of thermogenesis in mammals. Experimental Physiology, 93:773-797.

National Institutes of Health (2011). Serotonin helps control body temperature and breathing. NIH Research Matters. U.S. Department of Health and Human Services.

Osorio, J. (2015). The contagion of drug violence: Spatiotemporal dynamics of the mexican war on drugs. Journal of Conflict Resolution, 59(8):1403-1432.

Pokorny, A., Davis, F., and Harberson, W. (1963). Suicide, suicide attempts, and weather. The American Journal of Psychiatry.

Preti, A., Lentini, G., and Maugeri, M. (2007). Global warming possibly linked to an enhanced risk of suicide: Data from italy, 1974-2003. Journal of Affective Disorders, 102:29-25.

Preti, A. and Miotto, P. (1998). Influence of method on seasonal distribution of attempted suicided in italy. Psychiatry Research.

Qi, X., Tong, S., and Hu, W. (2009). Preliminary spatiotemporal analysis on the association between socio-environmental factors and suicide. Environmental Health, 8(46).

Ranson, M. (2014). Crime, weather, and climate change. Journal of Environmental Economics and Management, 67(3):274-302.

Ray, R., Corcoran, A., Brust, R., Kim, J. C., Richerson, G., Nattie, E., and Dymecki, S. (2011). Impaired respiratory and body temperature control upon acute serotonergic neuron inhibition. Science, 333.

Rios, V. (2013). Why did Mexico become so violent? A self-reinforcing violent equilibrium caused by competition and enforcement. Trends in Organized Crime, 16(2).

Rios, V. (2014). Violence causes forced migration in Mexico. Latin American Research Review, 49(3).

Robles, G., Calderón, G., and Magaloni, B. (2014). The economic consequences of drug trafficking violence in mexico. Working Paper. 
Rohden, H. (1933). Einfluss des Fohns auf das korperlich-seelische Befinden. Akad. Verlagsgesellschaft.

Rohles, F. H. (1967). Environmental psychology-bucket of worms. Psychology today, 1(2):5463.

Rozo, S. V. (2019). Is murder bad for business? evidence from colombia. Review of Economics and Statistics.

Ruuhela, R., Hiltunen, L., Venalainen, A., Pirinen, P., and Partonen, T. (2009). Climate impact on suicide rates in finland from 1971 to 2003. International Journal of Biometeorology, 53:167-175.

Salib, E. and Gray, N. (1997). Weather conditions and fatal self-harm in north cheshire 1989-1993. British Journal of Psychiatry, 171:473-477.

Seo, D., Patrick, C., and Kennealy, P. (2008). Role of serotonin and dopamine system interactions in the neurobiology of impulsive aggression and its comorbidity with other clinical disorders. Agression and Violent Behavior, 13(5):383-395.

Serneels, P. and Verpoorten, M. (2013). The impact of armed conflict on economic performance: Evidence from rwanda. Journal of Conflict Resolution.

Shemyakina, O. (2011). The effect of armed conflict on accumulation of schooling: Results from tajikistan. Journal of Development Economics, 95:186-200.

Singh, P. (2012). Impact of terrorism on investment decisions of farmers: Evidence from the punjab insurgency. Journal of Conflict Resolution, 57(1):143-168.

Skoufias, E. (2012). The poverty and welfare impacts of climate change: Quantifying the effects, identifying the adaptation strategies. World Bank.

Skoufias, E., Davis, B., and de la Vega, S. (2001). Targeting the poor in Mexico: An evaluation of the selection of households into PROGRESA. World Development, 29:17691784 .

Souetre, E., Wehr, T. A., Douillet, P., and Darcourt, G. (1990). Influence of environmental factors on suicidal behavior. Psychiatry Research, 32:253-263.

Tauchen, H., Witte, A., and Long, S. (1991). Domestic violence: A non-random affair. International Economic Review, 32(2):491-511.

The Economist (2012). The ebbing mexican wave. The Economist.

Toro, K., Dunay, G., Barholy, J., Pongracz, R., Kis, Z., and Keller, E. (2009). Relationship between suicidal cases and meteorological conditions. Journal of Forensic and Legal Medicine, 16:277-279.

Tsai, J.-F. (2010). Socioeconomic factors outweigh climate in the regional difference of suicide death rate in taiwan. Psychiatry Research, 179:212-216. 
Velasquez, A. (2019). The economic burden of crime: Evidence from mexico. Journal of Human Resources.

Verwimp, P. and Van Bavel, J. (2014). Schooling, violent conflict, and gender in burundi. World Bank Economic Review, 28(2):384-411.

Voors, M. J. (2014). Conflict and the evolution of institutions: Unbundling institutions at the local level in burundi. Journal of Peace Research, 51(4):455-469.

Vrij, A., Van der Steen, J., and Koppelaar, L. (1994). Aggression of police officers as a function of temperature: An experiment with the fire arms training system. Journal of community $\&$ applied social psychology, 4(5):365-370.

Werner, J. (1980). The concept of regulation for human body temperature. Journal of Thermal Biology, 5(2):75-82.

Willmott, C. J. and Matsuura, K. (2014). Global (land) precipitation and temperature. Climate Data Guide.

Yan, Y. Y. (2000). Geophysical variables and behavior: Lxxxxix. the influence of weather on suicide in hong kong. Perceptual and Motor Skills, 91:571-577.

Yang, A. C., Tsai, S.-J., and Huang, N. E. (2011). Decomposing the association of completed suicide with air pollution, weather, and unemployment data at different time scales. Journal of Affective Disorders, 129:275-281. 


\section{Figure 1: Spectrum of violence}

\begin{tabular}{|c|c|c|c|c|c|c|}
\hline Type of violence & Institutional & Interg & roup & & Interpersonal & Intrapersonal \\
\hline Examples & $\begin{array}{l}\text { institutional change } \\
\text { population collapse } \\
\text { civilization collapse }\end{array}$ & $\begin{array}{c}\text { coups } \\
\text { civil conflict } \\
\text { civil war } \\
\text { interstate conflict }\end{array}$ & $\begin{array}{c}\text { riots } \\
\text { ethnic expulsion } \\
\text { land invasions }\end{array}$ & $\begin{array}{c}\text { gang killings } \\
\text { (this study) }\end{array}$ & $\begin{array}{c}\text { homicide } \\
\text { assault } \\
\text { rape } \\
\text { road rage } \\
\text { sports violence }\end{array}$ & $\begin{array}{c}\text { suicide } \\
\text { (this study) }\end{array}$ \\
\hline Selected literature & $\begin{array}{l}\text { Haug et al (2003) } \\
\text { Buckley et al (2010) }\end{array}$ & $\begin{array}{c}\text { Harari and La Ferrara (2018) } \\
\text { Fetzer (2019) } \\
\text { Hsiang et al (2011) } \\
\text { Burke et al (2009) }\end{array}$ & $\begin{array}{l}\text { Hidalgo et al (2010) } \\
\text { Bohlken and Sergenti (2010 }\end{array}$ & & $\begin{array}{l}\text { Ranson (2014) } \\
\text { Larrick et al (2011) } \\
\text { Jacob et al (2007) }\end{array}$ & $\begin{array}{l}\text { Burke et al (2018) } \\
\text { Dixon et al (2007) }\end{array}$ \\
\hline
\end{tabular}

Figure 2: Time series of violence

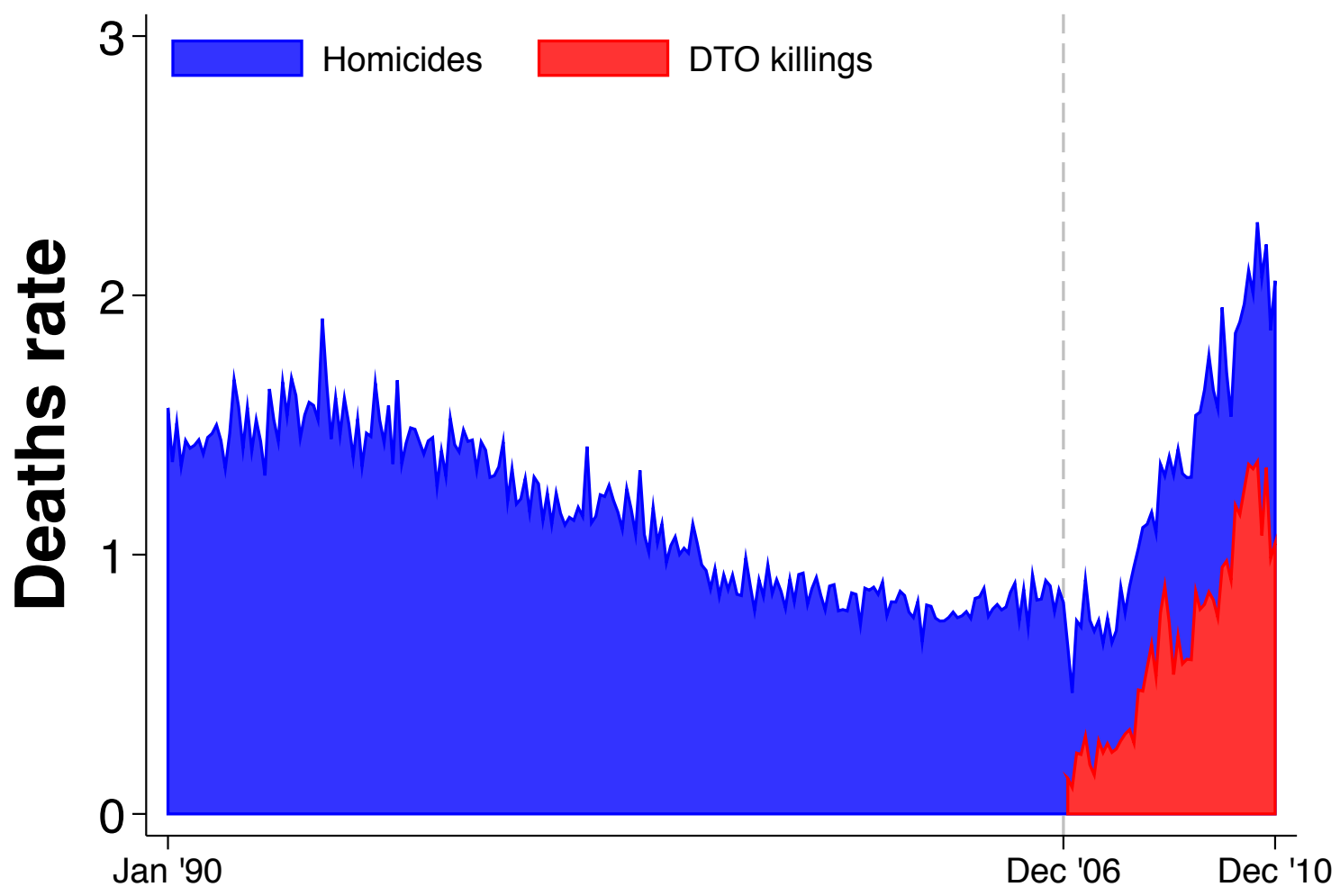

Notes: Time averages (weighted by population) for our main outcome variables in all municipalities in Mexico. The dash vertical black line denotes the beginning of the Mexican Drug War. 
Figure 3: Temperature and violence in Mexico
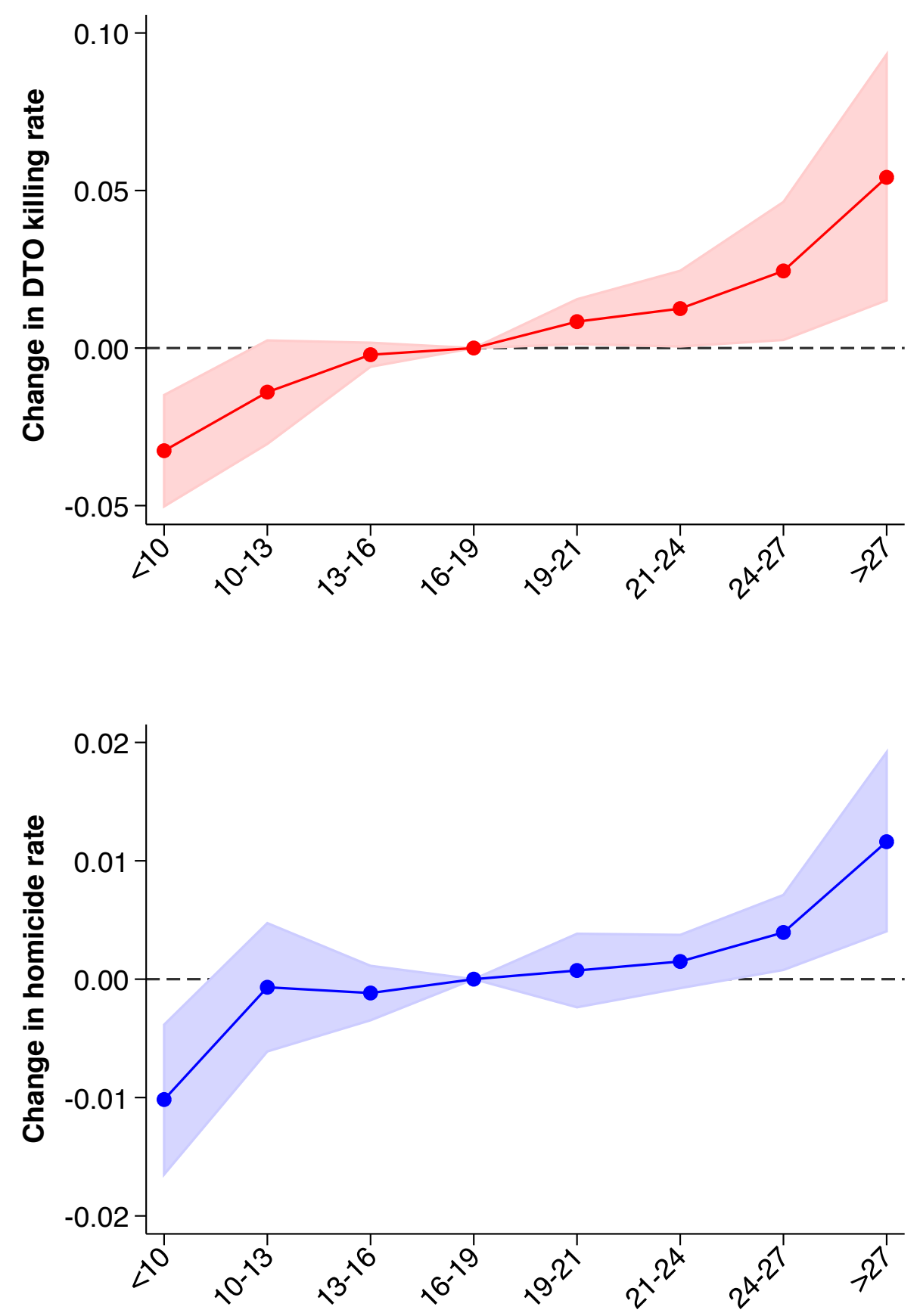

Notes: These figures present non-parametric estimates of equation (3). Temperature response functions for DTO killings (upper panel) and homicides (lower panel) using temperature bins of width $3^{\circ} \mathrm{C}$. The $x$-axis is interpreted as the average temperature in a given municipality-month, and the $y$-axis is interpreted as deviation from that municipalitymonth average in the corresponding measure of violence. 
Figure 4: Meta-analysis

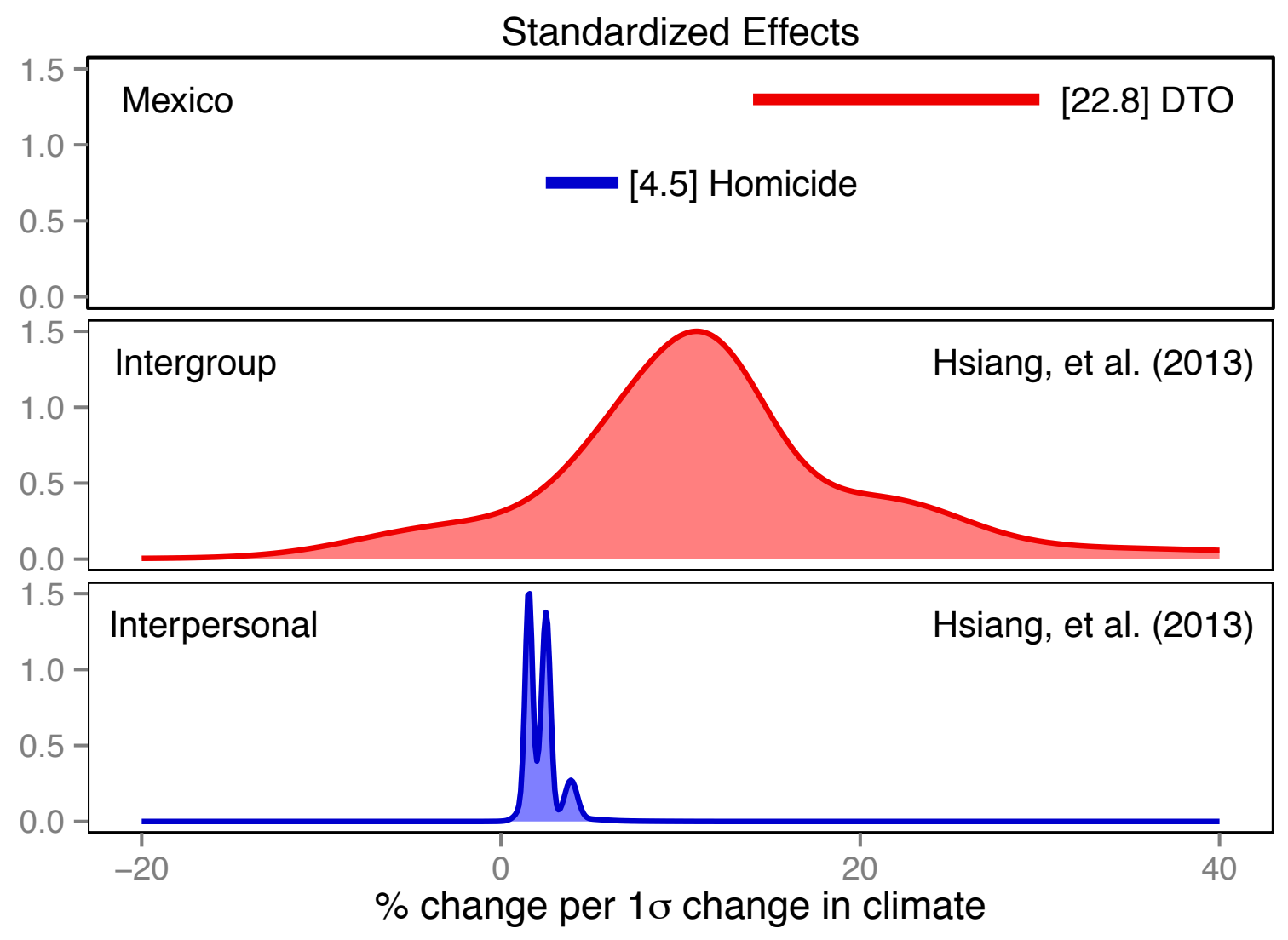

Notes: Top panel presents estimated standardized effects and confidence intervals from this study. Bottom panels show the distribution of standardized effects of climate on interpersonal (e.g. rapes) and intergroup (e.g. civil conflict) outcomes from Hsiang et al. (2013). 
Figure 5: Temperature and suicides

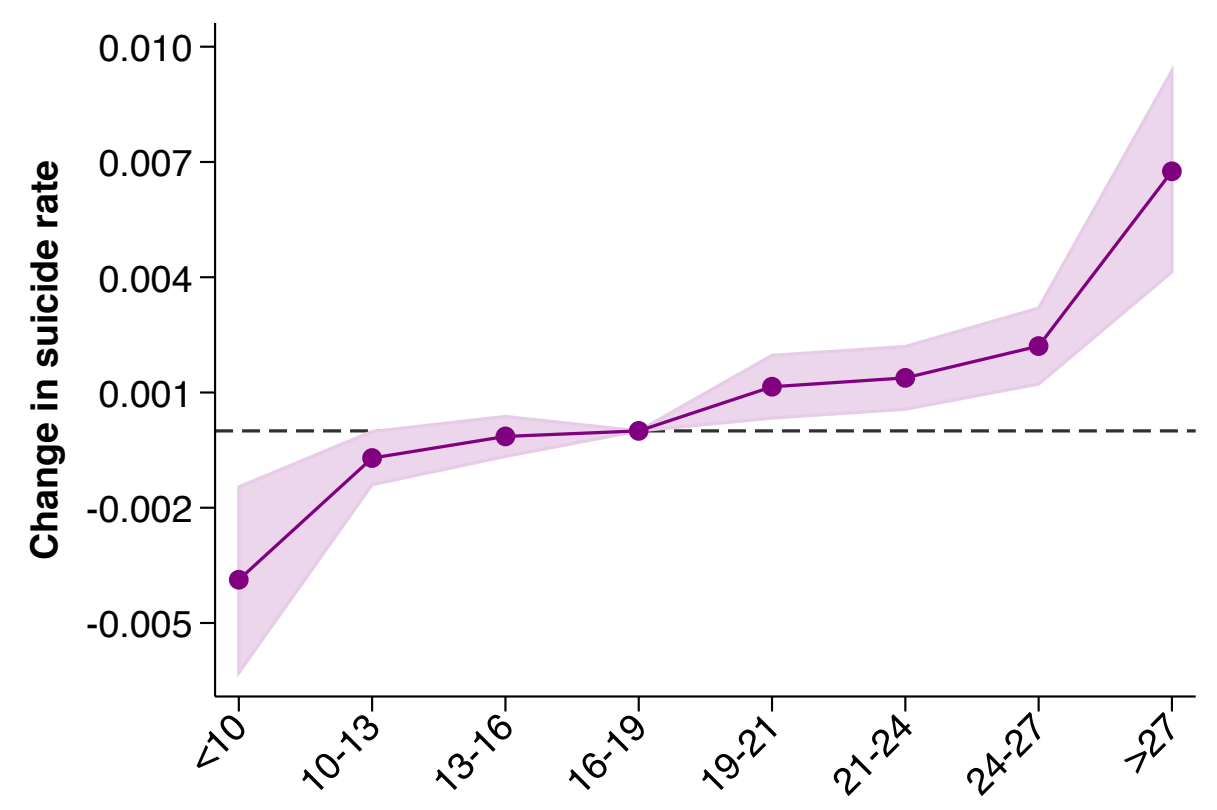

Notes: This figure presents non-parametric estimates of equation (3). These temperature response functions use bins of width $3^{\circ} \mathrm{C}$. The $x$-axis is interpreted as the average temperature in a given municipality-month, and the $y$-axis is interpreted as deviation from that municipality-month average in suicides per 100,000 inhabitants. 
Figure 6: Temporal distribution of estimates
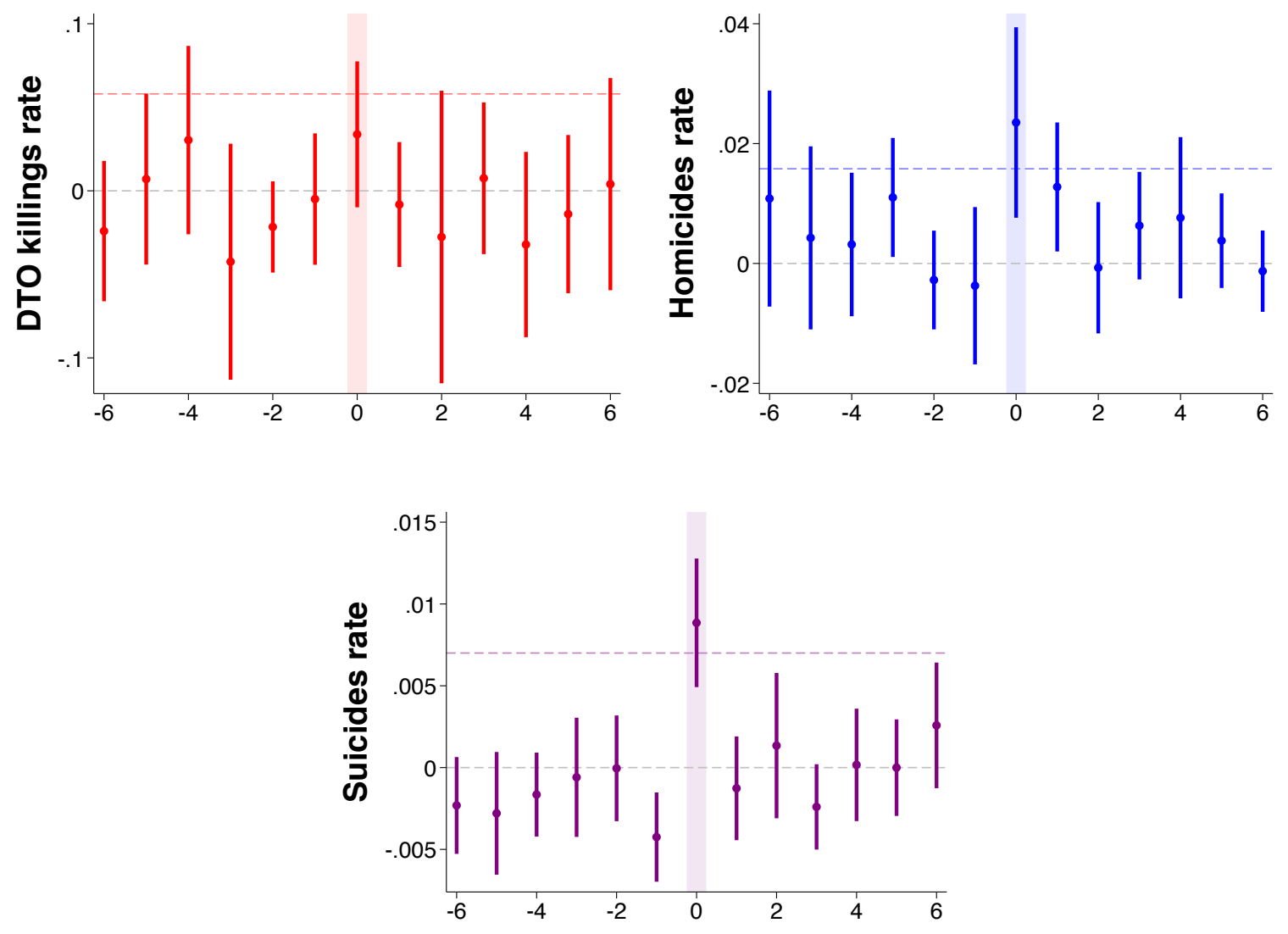

Notes: This figure shows regression estimates $\beta_{t+k}$ from Equation 4. 


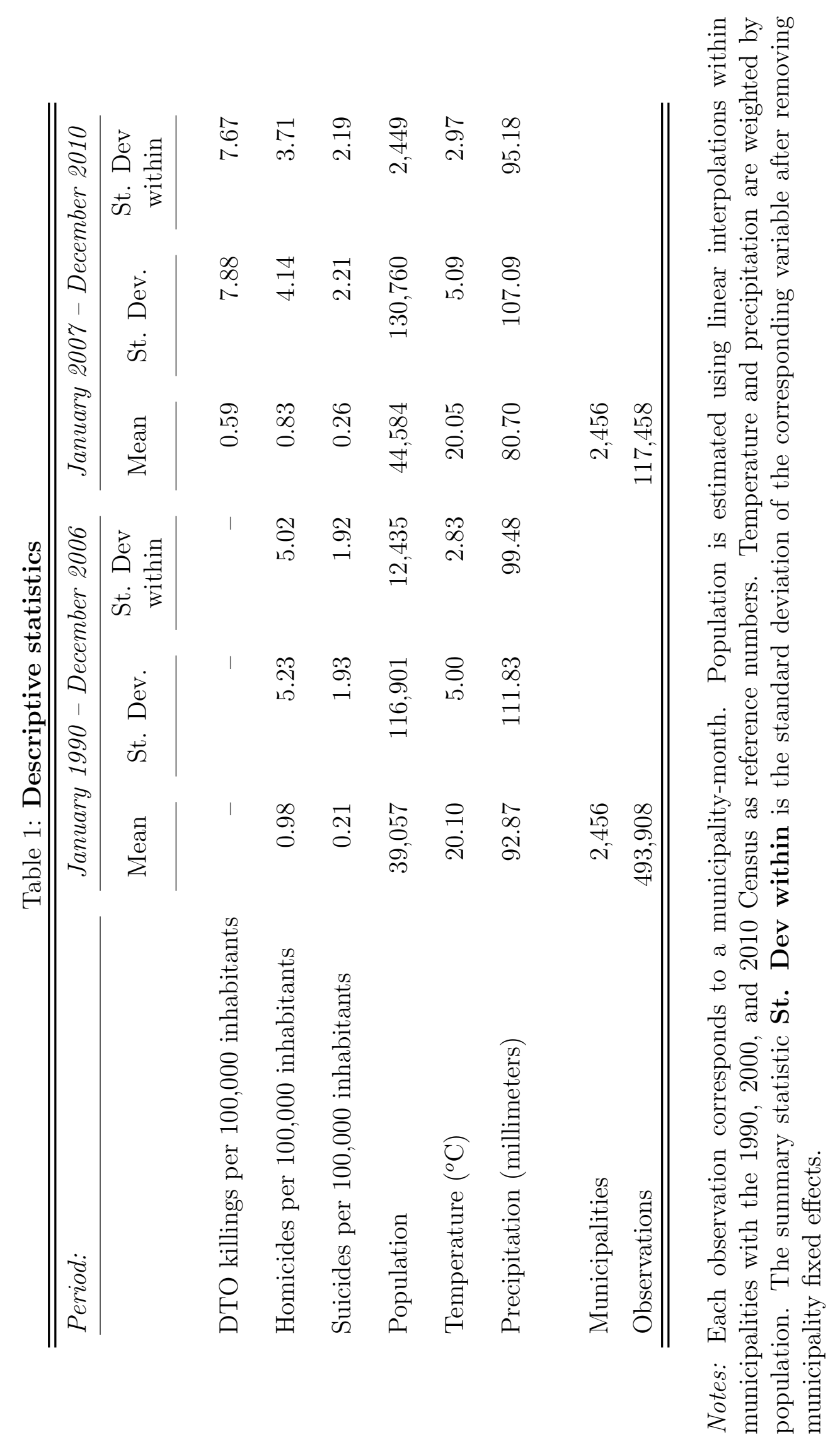


Table 2: Temperature and violence in Mexico

\begin{tabular}{|c|c|c|c|c|c|c|}
\hline \multirow[t]{2}{*}{ Dependent variable: } & \multicolumn{3}{|c|}{ DTO killings } & \multicolumn{3}{|c|}{ Homicides } \\
\hline & (1) & $(2)$ & $(3)$ & (4) & $(5)$ & (6) \\
\hline \multirow[t]{3}{*}{ Temperature } & $0.058^{* *}$ & $0.066^{* *}$ & $0.053^{* * *}$ & $0.016^{* * *}$ & $0.023^{* *}$ & $0.014^{* * *}$ \\
\hline & $(0.022)$ & $(0.030)$ & $(0.019)$ & $(0.004)$ & $(0.011)$ & $(0.003)$ \\
\hline & {$[28.4]$} & {$[33.6]$} & {$[26.9]$} & {$[4.7]$} & {$[7.0]$} & {$[4.3]$} \\
\hline \multirow[t]{3}{*}{ Precipitation } & 0.016 & -0.013 & 0.025 & -0.004 & -0.001 & $-0.009^{*}$ \\
\hline & $(0.041)$ & $(0.027)$ & $(0.035)$ & $(0.007)$ & $(0.007)$ & $(0.005)$ \\
\hline & {$[2.7]$} & {$[-2.2]$} & {$[4.2]$} & {$[-0.4]$} & {$[-0.1]$} & {$[-0.9]$} \\
\hline Municipality F.E. & Yes & Yes & Yes & Yes & Yes & Yes \\
\hline Year F.E. & Yes & Yes & Yes & Yes & Yes & Yes \\
\hline Month F.E. & Yes & No & Yes & Yes & No & Yes \\
\hline Month-state F.E. & No & No & Yes & No & No & Yes \\
\hline State trends & No & Yes & No & No & Yes & No \\
\hline Observations & 117,458 & 117,458 & 117,458 & 493,908 & 493,908 & 493,908 \\
\hline
\end{tabular}

Notes. Each observation corresponds to a municipality-month. Estimates of equation (3) using data for all municipalities in Mexico in different periods (2007-2010 in columns 1-3, 1990-2006 in columns 4-6). State trends is a complete set of year indicators interacted with state indicators. Standard errors clustered at the state level in parenthesis. Standardized effects in brackets. All regressions are weighted by population. Levels of significance are reported as $* * * \mathrm{p}<0.01,{ }^{*} \mathrm{p}<0.05,{ }^{*} \mathrm{p}<0.1$. 
Table 3: Temperature and economically motivated crimes

\begin{tabular}{|c|c|c|c|c|c|}
\hline \multirow[t]{2}{*}{ Dependent variable: } & DTO killings & Homicides & Car thefts & Extortions & Kidnappings \\
\hline & $(1)$ & $(2)$ & (3) & (4) & (5) \\
\hline Temperature & $\begin{array}{c}0.050 * * \\
(0.024) \\
{[22.8]}\end{array}$ & $\begin{array}{c}0.050 * * \\
(0.023) \\
{[13.7]}\end{array}$ & $\begin{array}{c}0.067 \\
(0.092) \\
{[1.7]}\end{array}$ & $\begin{array}{c}-0.005 \\
(0.004) \\
{[-4.5]}\end{array}$ & $\begin{array}{c}-0.001 \\
(0.001) \\
{[-3.1]}\end{array}$ \\
\hline Precipitation & $\begin{array}{c}0.080 \\
(0.447) \\
{[0.8]}\end{array}$ & $\begin{array}{c}-0.285 \\
(0.411) \\
{[-1.7]}\end{array}$ & $\begin{array}{c}-0.363 \\
(2.430) \\
{[-0.2]}\end{array}$ & $\begin{array}{c}0.220 \\
(0.255) \\
{[3.9]}\end{array}$ & $\begin{array}{c}0.060 \\
(0.036) \\
{[6.2]}\end{array}$ \\
\hline $\begin{array}{l}\text { Mean of dep. variable } \\
\text { (Within st. dev.) }\end{array}$ & $\begin{array}{c}0.737 \\
(0.962)\end{array}$ & $\begin{array}{l}1.217 \\
(0.827)\end{array}$ & $\begin{array}{l}13.414 \\
(5.600)\end{array}$ & $\begin{array}{c}0.407 \\
(0.360)\end{array}$ & $\begin{array}{l}0.070 \\
(0.088)\end{array}$ \\
\hline Municipality, year \& month F.E. & Yes & Yes & Yes & Yes & Yes \\
\hline Observations & 1,536 & 1,535 & 1,535 & 1,535 & 1,534 \\
\hline $\mathrm{R}^{2}$ & 0.649 & 0.714 & 0.886 & 0.603 & 0.392 \\
\hline
\end{tabular}

Notes. Each observation corresponds to a state-month. Estimates using data for all states in Mexico in the period 2007 - 2010. All dependent variables are rates per 100,000 inhabitants. Source is Secretariado Ejecutivo del Sistema Nacional de Seguridad Pública (SESNSP). Standard errors clustered at the state level in parenthesis. Standardized effects in brackets. Levels of significance are reported as ${ }^{* * *} \mathrm{p}<0.01,{ }^{* *} \mathrm{p}<0.05,{ }^{*} \mathrm{p}<0.1$. 


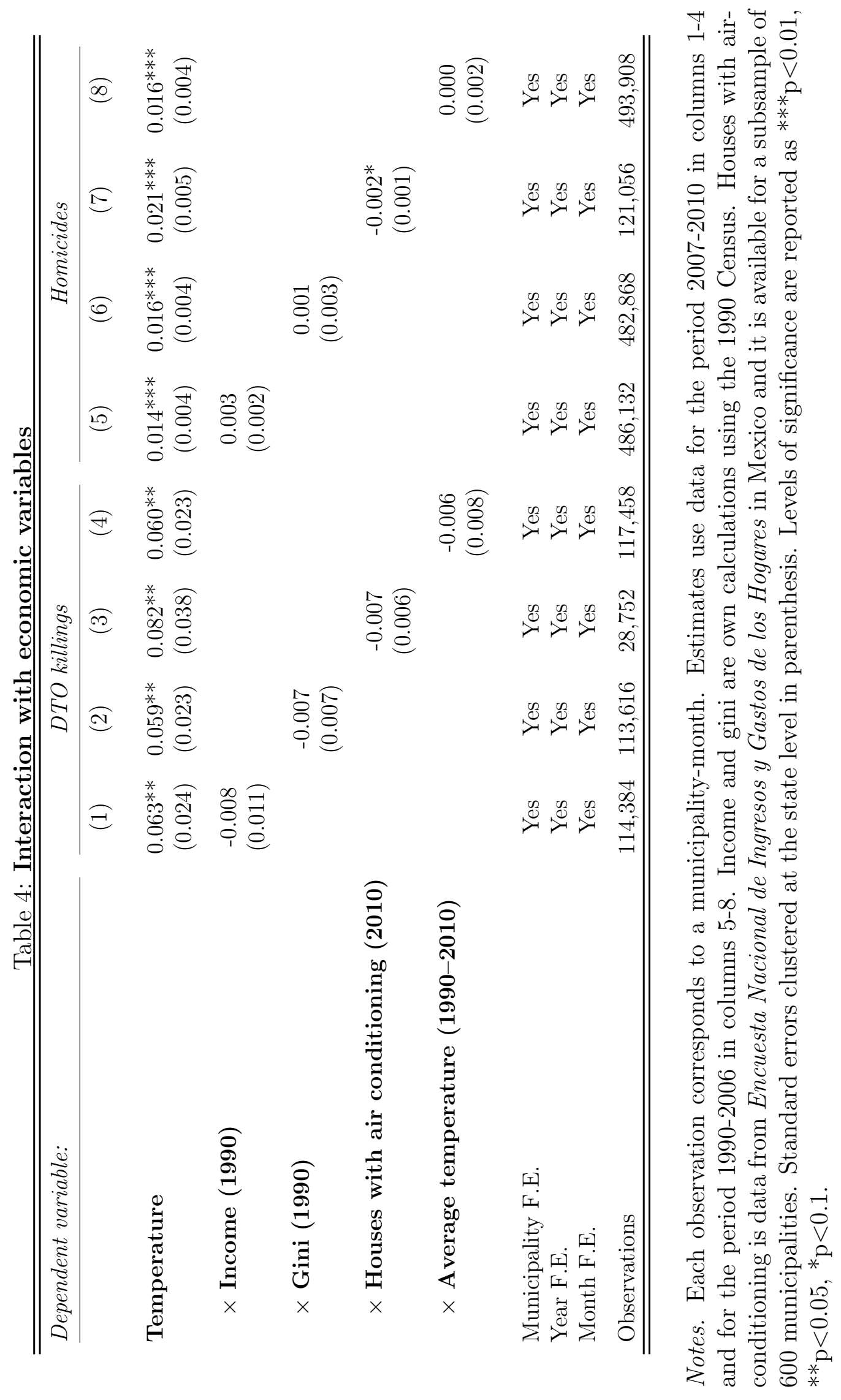




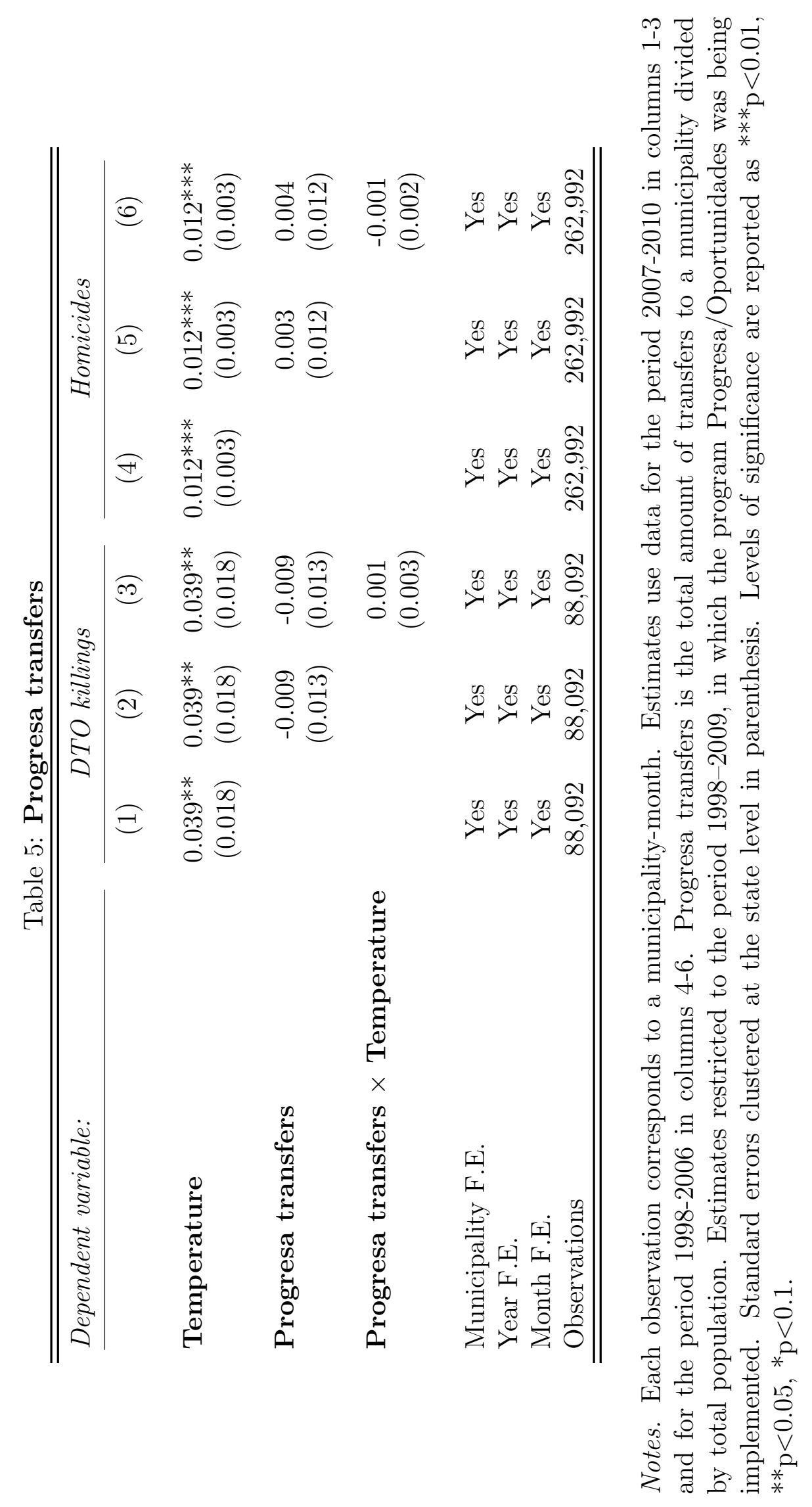




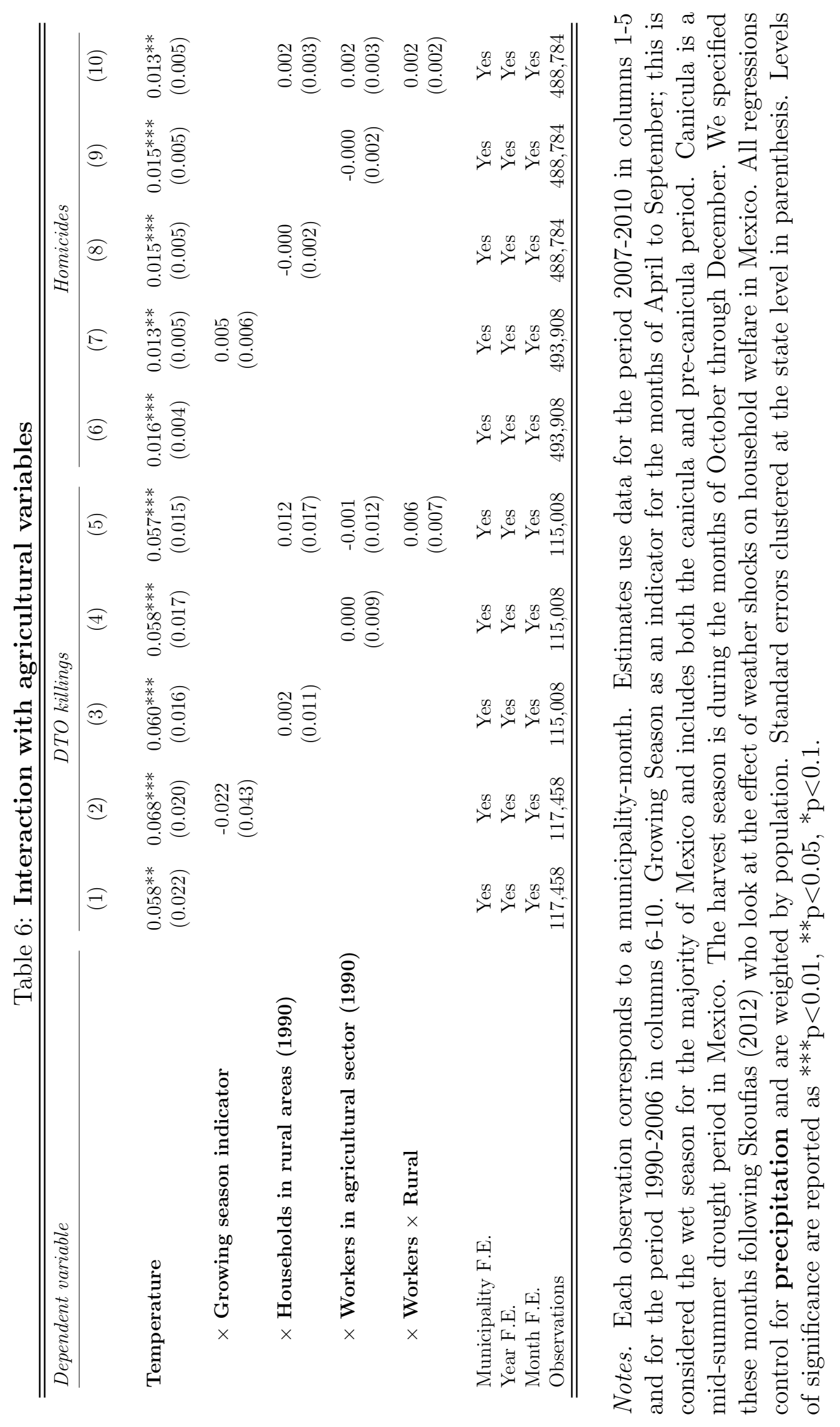




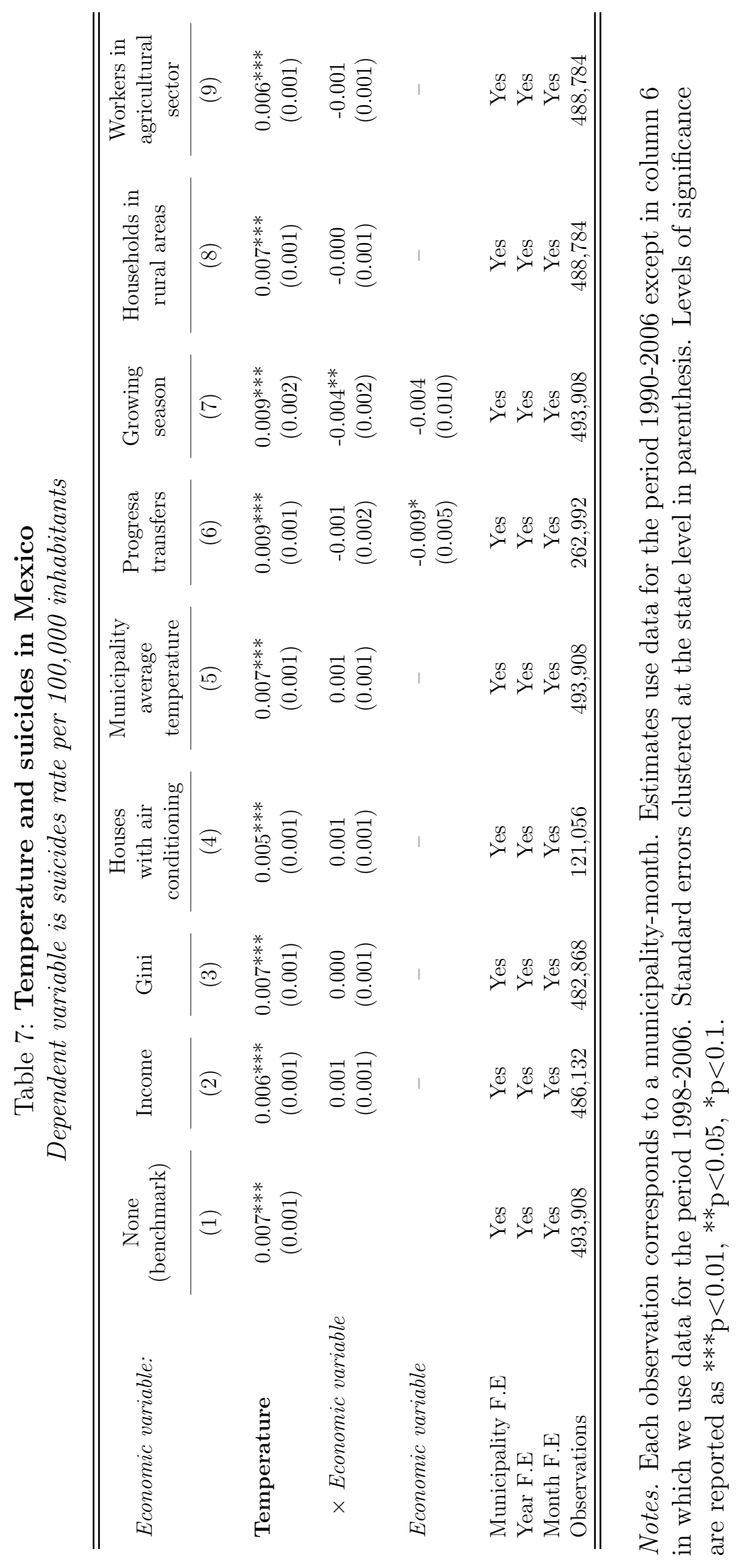




\section{ONLINE APPENDIX}

\section{Non-Economic Factors in Violence:}

Evidence from Organized Crime, Suicides and Climate in Mexico

\section{A Literature Review}

\section{A.1 Consequences of violence}

There is a large literature in economics and political science documenting the negative effects of crime, conflict, and war (from now on "conflict") on different outcomes. For example, in relatively new papers researchers have documented the effect conflict has on health outcomes (Bundervoet et al. 2009, Baez 2011, Akresh 2012, Akbulut-Yuksel 2014b), human capital formation (Blattman and Annan 2010, Shemyakina 2011, Chamarbagwala and Moran 2011, León 2012, Verwimp and Van Bavel 2014, Akbulut-Yuksel 2014a), labor outcomes (Kondylis 2010, Fernandez et al. 2011, Bozzoli et al. 2012), consumption (Serneels and Verpoorten 2013, Velasquez 2019), agricultural investment (Singh, 2012), firm exit (Camacho and Rodriguez, 2012), family formation (Akbulut-Yuksel et al., 2013), wages and prices (Rozo, 2019), and the development of institutions (Voors, 2014). Reviewing this large literature is beyond the scope of this paper, but it is clear that conflict has increasingly negative and pervasive effects in societies. ${ }^{21}$

Researchers have also started to document the consequences of the dramatic increase in violence after 2007 in Mexico. For example, Rios (2014) shows that cities on the U.S.-Mexico border have received relatively more Mexican immigrants in recent years, despite the fact that Mexican immigration to the U.S. reached its lowest point since 2000 across the country as a whole (Cave 2011, The Economist 2012). Other researchers have estimated the impact on labor markets. Robles et al. (2014) use an instrumental variables approach and finds that violence has had negative effects on labor participation and unemployment, and caused a decrease in local economic activity. ${ }^{22}$ In the same line of research, Velasquez (2019) uses a differences-in-differences approach at the individual level and finds that increased violence (i) decreases labor market participation and the number of hours worked by self-employed women, (ii) decreases hourly and total earnings of self-employed males, and (iii) decreases per capita expenditure. In addition, Brown (2018) findings suggest that the escalation of violence decreased average birth weight by 70 grams $(\sim 40$ percent), and by $\sim 120$ for mothers with low socioeconomic status. ${ }^{23}$ In a related study, Leiner et al. (2012) results

\footnotetext{
${ }^{21}$ See Blattman and Miguel (2010) for a review of the literature before 2010, and Miguel and Roland (2011) for long-run consequences of violent events.

${ }^{22}$ The same authors also find evidence of spillovers from homicides to other criminal activities such as extortions, kidnappings, and car thefts, something also noted by Guerrero (2010) and Brown (2018).

${ }^{23}$ For comparison, this effect is larger than estimates of the positive impact on birth weight of federal
} 
suggest that exposure to violence causes mental health problems (e.g. depression, anxiety, attention, aggressive behavior).

\section{A.2 Seasonality in suicides}

For empirical studies analyzing the relationship between temperature and suicides see Rohden (1933), Mills (1934), Pokorny et al. (1963), Grove and Lynge (1979), Dixon and Shulman (1983), Chiu (1988), Marion et al. (1990), Souetre et al. (1990), Linkowski et al. (1992), Barker et al. (1994), Salib and Gray (1997), Jessen et al. (1998), Preti and Miotto (1998), Yan (2000), Leung et al. (2002), Deisenhammer et al. (2003), Lee et al. (2006), Ajdacic-Gross et al. (2007), Preti et al. (2007), Hajat et al. (2007), Qi et al. (2009), Toro et al. (2009), Ruuhela et al. (2009), Tsai (2010), Likhvar and Honda (2011), Kim et al. (2011), Yang et al. (2011), Inoue et al. (2012),Helama et al. (2013), Holopainen et al. (2013). See Ajdacic-Gross et al. (2010) and Christodoulou et al. (2012) for a review of the literature on the seasonality of suicides, Deisenhammer (2003) for a review of the literature on weather and suicides until 2003. See Burke et al. (2018) for a summary of the more recent studies.

\section{B Additional Data}

In this section we describe our additional data sources and the construction of variables associated with it. We proceed describing variables in the same order that they appear on the main text.

\section{B.1 Drug Trafficking Organizations}

We use a number of variables related to the presence of a drug trafficking organization (DTO) in a state. In particular, we use two sets of variables: (1) the number of DTOs operating in a state $s$ in year $t$, and (2) the shares of the state where the DTOs "Sinaloa" and "Zetas" operate. We define a share of some DTO as the total number of municipalities where that DTO operates over total number of municipalities in that state. We chose these two DTOs because anecdotal evidence (and some quantitative evidence we show later on) shows that the Zetas have been trying to take control over the territory controlled by Sinaloa, and hence many DTO killings seem to be associated with this rivalry.

The data we use to construct these variables comes from Coscia and Rios (2012). These authors use newspapers and blogs, aggregated through Google News, as sources of information to estimate where DTOs operate. In particular, they generate a panel dataset of all municipalities in Mexico, observed yearly between 1990 and 2010, with ten indicator variables (one for each DTO). These indicator variables take the value of one if the corresponding DTO is operating in that municipality.

nutrition programs such as the Supplemental Nutrition Program for Women, Infants, and Children, and the Food Stamp Program in the United States. 
There are two main differences between this DTO dataset and ours. First, we work with states in our analysis, while DTO operations are recorded at the municipality level. Second, our time interval is a month, while DTO operations are recorded on a yearly basis. To facilitate exposition, let $k=1, \ldots, 10$ represent a certain DTO. To merge DTO operations with our dataset we collapse the yearly data at the state level and create (i) a series of indicator variables $D T O_{k s t}$ that take the value of one if a DTO $k$ is operating in state $s$ and year $t$, and (ii) the corresponding state shares previously described. When doing this we assign yearly information to all months in that year.

Then, we construct our three main variables in the following way. The variable DTOs is simply the sum of DTOs operating in state $s$ and year $t$, i.e. $D T O_{s t}=\sum_{k=1}^{10} D_{k s t}$. The shares are defined as previously mentioned. In order to show some evidence for the rivalry between Sinaloa and the Zetas, we collapsed our dataset at the state-year level and ran the following regression:

$$
y_{s t}=\alpha+\lambda_{t}+\zeta_{s}+\sum_{k=1}^{10} \beta_{k} D T O_{k s t}+\varepsilon_{s t}
$$

where $y_{s t}$ is DTO killings for each 100,000 inhabitants, $\alpha$ is a constant term, $\lambda_{t}$ is a year fixed effect, $\zeta_{s}$ is a state fixed effect, $D T O_{k s t}$ are ten indicator variables, and $\varepsilon_{s t}$ is an error term clustered at the state level. Then, a DTO $k$ is classified as violent if $\beta_{k}>0$ and is statistically significant. Figure A.3 presents estimates of this regression equation. Note that the Zetas are operating in every state-month in our sample, so these regression estimates effectively show how DTO killings respond to the presence of DTO pairs of Zetas and another organization. We can see from this figure that the only DTO pair that is statistically associated with DTO killings is the one Zetas-Sinaloa. Sinaloa operates in 46 percent of state-years in our sample period. Descriptive statistics for all these variables are presented in Table A.2.

\section{B.2 Criminal activities}

In Table 6 we use a different data source to measure (1) homicides, and we add three variables measuring criminal activities that have a clear economic objective: (2) kidnappings, (3) extortions, and (4) car thefts. This data was collected by the Secretariado Ejecutivo del Sistema Nacional de Seguridad Pública (SESNSP) at the Mexican Secretariat of the Interior (Secretaría de Gobernación).

To incorporate this information into our dataset we downloaded it from the website of the Mexican Secretariat of the Interior. The raw data is transformed into rates per 100,000 inhabitants in the state using population census data. The only exception is car thefts. When using this variable we add up the raw variables robo de vehiculo con violencia (violent car theft), and robo de vehículo sin violencia (non-violent car theft) to create a variable we call "car thefts". There are, on average, 39 homicides, 2.4 kidnappings, 13 extortions, and 515 car thefts in a state-month in the period between January of 2007 and December of 2010. Table A.2 presents descriptive statistics for these variables in rates, showing the

overall standard deviation, and the deviation after removing state, year, and month fixed 
effects.

Although these variables are available at the state-month level for the period 1997-2014, we only use them for the period 2007-2010 to be consistent with our empirical analysis. Finally, we refer the reader to Merino (2011) for a comparison between this alternative homicide variable and the two variables we use in our main empirical analysis (i.e. DTO killings and homicides from Mexico's Bureau of Statistics).

\section{B.3 Economic variables}

In Table 4 we use a series of economic variables. Log GDP per capita is measured in 1999 at 1993 prices and the source is Mexico's Bureau of Statistics (INEGI). Houses with airConditioning is the saturation of residential air-conditioning, from the National Household Income and Expenditure Survey of 2010 (Encuesta Nacional de Ingresos y Gastos de los Hogares), officially managed by the Mexico's National Bureau of Statistics since 1984. This is a nationally representative survey of rural and urban areas. This measure is based on an indicator variable for whether a household has an air-conditioning unit, which falls under the category of durable goods. This measure was then aggregated to the state level using ENIGH sampling weights. Gini is an income inequality index constructed by Jensen and Rosas (2007) using the 1990 and 2000 Mexican national census. The authors calculate the Gini indices using methods proposed by Abounoori and McCloughan (2003) and Milanovic (1994). Finally, Unemployment is monthly unemployment data for each state from the National Survey of Employment and Occupation, and is available since March of 2005 until the end of our period of study.

\section{B.4 Progresa transfers}

In Table 3 we use variation in income generated by the program OpORTUNIDADES in Mexico. This social program started in 1997 with the name of PROGRESA (Programa de Educación y Salud, Education and Health Program), and it consisted of conditional cash transfers that targeted poor families in marginal rural areas between 1997 and 2002. A main feature of this program is that it included an evaluation component from its inception. From 2002 the program changed its name and scope and began to incorporate urban areas as well. The budget for this program was approximately 133 million USD in 1997 ( 0.03\% of GDP), and it has expanded to almost 5 billion USD in $2010(\sim 0.5 \%$ of GDP).

We downloaded bimonthly monetary transfers to each state from the program's official website. This information is available for the OpORTUNIDADES program, i.e. from 2002 onwards. In our empirical analysis we use the logarithm of one plus the total amount of bimonthly transfer to a state. Less than $2 \%$ of observations correspond to no monetary transfers (i.e. transfer equals zero) in the period we analyze. We take a bimonthly transfer, e.g. 100 USD in January-February, and we split it equally between both months, i.e. 50 USD in January and 50 USD in February. Descriptive statistics for this variable are presented in Table A.2. 


\section{B.5 Wage and unemployment}

In Panels A and B of Figure A.6 we plot the average bimonthly income and unemployment of agricultural and non-agricultural workers in Mexico. To construct this data we use the National Household Survey of Income and Expenditure (Encuesta Nacional de Ingresos y Gastos de los Hogares), officially managed by the Mexico's National Bureau of Statistics since 1984. This is a nationally representative survey of rural and urban areas, and is done every two years since 1992. For these calculations we use the years 1989, 1992, 1994, 1996, 1998, 2000, 2002, and 2004.

The interviews for this survey are done between the months of July and October. One part of this questionnaire constructs, retrospectively, workers' income in the past 6 months. In addition, the occupation of the individual is always part of this questionnaire. Exploiting variation in the distribution of interviews, and classifying individuals in the agricultural and non-agricultural sectors, we were able to construct (i) average monthly income, and (ii) percentage of individuals without income, both from February to October. Finally, we construct two months bins from these numbers to estimate seasonality in income and unemployment for both sectors. 
Table A.1: Operation of Mexican drug cartels

\begin{tabular}{|c|c|c|c|c|c|}
\hline Cartel & $\begin{array}{l}\text { Municipalities } \\
\text { in } 2010\end{array}$ & $\begin{array}{l}\text { Start } \\
\text { Year }\end{array}$ & Entry & Exit & $\begin{array}{c}\text { Years } \\
\text { Operated }\end{array}$ \\
\hline Sinaloa & 176 & 1993 & 25.6 & 17.0 & 2.8 \\
\hline Golfo & 244 & 1994 & 35.6 & 23.5 & 3.0 \\
\hline Juárez & 74 & 1997 & 13.9 & 10.2 & 2.8 \\
\hline Tijuana & 39 & 1997 & 10.1 & 8.2 & 2.7 \\
\hline Zetas & 405 & 2003 & 42.2 & 22.0 & 2.8 \\
\hline Beltrán-Leyva & 157 & 2004 & 18.7 & 10.8 & 2.1 \\
\hline Fam & 227 & 2005 & 18.8 & 7.4 & 2.1 \\
\hline Barbie & 66 & 2006 & 5.8 & 2.5 & 1.6 \\
\hline Mana & 32 & 2006 & 3.8 & 2.2 & 2.2 \\
\hline Sinaloa* & 53 & 2008 & 5.2 & 2.5 & 2.0 \\
\hline Beltrán-Leyva* & 57 & 2008 & 5.0 & 2.2 & 1.8 \\
\hline Other & 24 & 2008 & 2.2 & 1.0 & 1.4 \\
\hline
\end{tabular}

Source: Table 1 in Coscia and Rios (2012). Entry is the average number of municipalities cartel $k$ enters in a year. Exit is the average number of municipalities cartel $k$ exits in a year. Years operated is the average number of years cartel $k$ operates in a municipality. ${ }^{*}$ Factionalized cartel. 
Table A.2: Descriptive statistics for additional variables

\begin{tabular}{|c|c|c|c|}
\hline Mean & St. Dev & $\begin{array}{c}\text { St. Dev } \\
\text { within }\end{array}$ & Min \\
\hline
\end{tabular}

Criminal activities

\begin{tabular}{|c|c|c|c|c|c|}
\hline Homicides & 1.22 & 1.54 & 0.83 & 0 & 11.92 \\
\hline Kidnappings & 0.07 & 0.11 & 0.09 & 0 & 0.90 \\
\hline Extortions & 0.41 & 0.57 & 0.36 & 0 & 5.91 \\
\hline Car thefts & 13.41 & 16.56 & 5.60 & 0 & 112.00 \\
\hline \multicolumn{6}{|c|}{ Drug trafficking organizations } \\
\hline DTOs & 6.30 & 2.47 & 0.92 & 1 & 10 \\
\hline Sinaloa & 0.03 & 0.05 & 0.03 & 0 & 0.27 \\
\hline Zetas & 0.21 & 0.21 & 0.08 & 0 & 0.94 \\
\hline \multicolumn{6}{|l|}{ Other } \\
\hline Log Progresa transfers & 17.24 & 3.75 & 2.88 & 0 & 20.16 \\
\hline
\end{tabular}

Notes: Descriptive statistics for all 32 Mexican states at the month level during the period between January of 2007 and December of 2010. 
Table A.3: Differential effect of temperature shocks by type of violence

\begin{tabular}{|c|c|c|c|c|}
\hline & \multicolumn{2}{|c|}{ Homicide rate } & \multicolumn{2}{|c|}{$\begin{array}{c}\text { Standardized } \\
\text { homicide rate }\end{array}$} \\
\hline & (1) & (2) & (3) & (4) \\
\hline Temperature & $\begin{array}{l}0.064^{*} \\
(0.034)\end{array}$ & $\begin{array}{l}0.073^{*} \\
(0.039)\end{array}$ & $\begin{array}{l}0.013^{*} \\
(0.007)\end{array}$ & $\begin{array}{l}0.018^{*} \\
(0.010)\end{array}$ \\
\hline$\times$ DTO killing & $\begin{array}{c}0.003 \\
(0.010)\end{array}$ & $\begin{array}{c}-0.015 \\
(0.020)\end{array}$ & $\begin{array}{c}-0.002 \\
(0.003)\end{array}$ & $\begin{array}{c}-0.010 \\
(0.007)\end{array}$ \\
\hline Municipality $(n)$, year $(y) \&$ month $(m)$ F.E. & Yes & No & Yes & No \\
\hline F.E. $n, y, m$ by type of violence & No & Yes & No & Yes \\
\hline Observations & 234,916 & 234,916 & 234,916 & 234,912 \\
\hline
\end{tabular}

Notes: Each observation corresponds to a municipality-type-month, where type is the homicide rate or the DTO killing rate. Data for all municipalities in Mexico in the 2007-2010 period . Standard errors clustered at the state level in parenthesis. The standardization in columns 3 and 4 takes the dependent variable and subtracts the type-specific mean and divides by the type-specific standard deviation. All regressions are weighted by population. Levels of significance are reported as ${ }^{* * *} \mathrm{p}<0.01,{ }^{* *} \mathrm{p}<0.05,{ }^{*} \mathrm{p}<0.1$. 
Table A.4: Including temperature in the previous month

\begin{tabular}{|c|c|c|c|c|c|c|}
\hline & \multicolumn{2}{|c|}{ DTO killings } & \multicolumn{2}{|c|}{ Homicides } & \multicolumn{2}{|c|}{ Suicides } \\
\hline & (1) & $(2)$ & $(3)$ & $(4)$ & $(5)$ & $(6)$ \\
\hline Temperature $_{t}(\alpha)$ & $\begin{array}{c}0.035^{* *} \\
(0.016)\end{array}$ & $\begin{array}{c}0.063 \\
(0.046)\end{array}$ & $\begin{array}{c}0.019^{* * * *} \\
(0.003)\end{array}$ & $\begin{array}{c}0.013^{* * *} \\
(0.004)\end{array}$ & $\begin{array}{c}0.011^{* * *} \\
(0.002)\end{array}$ & $\begin{array}{c}0.007 * * * \\
(0.002)\end{array}$ \\
\hline Temperature $_{t-1}(\beta)$ & $\begin{array}{c}0.020 \\
(0.036)\end{array}$ & & $\begin{array}{l}-0.007 \\
(0.004)\end{array}$ & & $\begin{array}{c}-0.006^{* * *} \\
(0.001)\end{array}$ & \\
\hline Temperature $_{t+1}(\beta)$ & & $\begin{array}{l}-0.017 \\
(0.032)\end{array}$ & & $\begin{array}{c}0.003 \\
(0.004)\end{array}$ & & $\begin{array}{c}0.000 \\
(0.002)\end{array}$ \\
\hline$\alpha+\beta$ & $\begin{array}{l}0.055^{*} \\
(0.032)\end{array}$ & $\begin{array}{c}0.046^{* *} \\
(0.019)\end{array}$ & $\begin{array}{c}0.012^{* * * *} \\
(0.004)\end{array}$ & $\begin{array}{c}0.015^{* * *} \\
(0.003)\end{array}$ & $\begin{array}{c}0.006^{* * *} \\
(0.002)\end{array}$ & $\begin{array}{c}0.007^{* * *} \\
(0.001)\end{array}$ \\
\hline State, year \& month F.E. & Yes & Yes & Yes & Yes & Yes & Yes \\
\hline Observations & 1,536 & 1,504 & 6,496 & 6,528 & 6,496 & 6,528 \\
\hline $\mathrm{R}^{2}$ & 0.649 & 0.644 & 0.697 & 0.697 & 0.472 & 0.470 \\
\hline
\end{tabular}

Notes: Estimates for all 32 states in Mexico. All regressions include state, year, and month fixed effects, and precipitation as control variable. Standard errors clustered at the state level in parenthesis. Levels of significance are reported as $* * * \mathrm{p}<0.01,{ }^{*} \mathrm{p}<0.05,{ }^{*} \mathrm{p}<0.1$. 
Table A.5: Drug trafficking organizations

\begin{tabular}{|c|c|c|c|c|c|}
\hline & \multicolumn{5}{|c|}{ Dependent variable is DTO killings } \\
\hline & (1) & $(2)$ & $(3)$ & $(4)$ & $(5)$ \\
\hline Temperature & $\begin{array}{l}0.050^{* *} \\
(0.024)\end{array}$ & $\begin{array}{c}0.049 * * \\
(0.024)\end{array}$ & $\begin{array}{c}0.048^{* *} \\
(0.024)\end{array}$ & $\begin{array}{l}0.049^{*} \\
(0.025)\end{array}$ & $\begin{array}{l}0.046^{*} \\
(0.025)\end{array}$ \\
\hline$\times$ DTOs & & $\begin{array}{c}0.005 \\
(0.004)\end{array}$ & & & \\
\hline$\times$ Sinaloa & & & $\begin{array}{c}0.279 \\
(0.317)\end{array}$ & & $\begin{array}{c}0.242 \\
(0.306)\end{array}$ \\
\hline$\times$ Zetas & & & & $\begin{array}{c}0.109 \\
(0.086)\end{array}$ & $\begin{array}{c}0.116 \\
(0.090)\end{array}$ \\
\hline$\times$ Sinaloa $\times$ Zetas & & & & & $\begin{array}{c}1.371 \\
(2.682)\end{array}$ \\
\hline DTOs & & $\begin{array}{c}0.071 \\
(0.082)\end{array}$ & & & \\
\hline Sinaloa & & & $\begin{array}{l}6.627^{* *} \\
(2.890)\end{array}$ & & $\begin{array}{l}6.909 * * \\
(2.794)\end{array}$ \\
\hline Zetas & & & & $\begin{array}{l}-0.021 \\
(0.983)\end{array}$ & $\begin{array}{c}0.203 \\
(1.011)\end{array}$ \\
\hline Sinaloa $\times$ Zetas & & & & & $\begin{array}{l}-21.777 \\
(27.452)\end{array}$ \\
\hline $\begin{array}{l}\text { Mean of dep. variable } \\
\text { (Within st. dev.) }\end{array}$ & $\begin{array}{c}0.737 \\
(0.962)\end{array}$ & & & & \\
\hline State, year \& month F.E. & Yes & Yes & Yes & Yes & Yes \\
\hline $\mathrm{R}^{2}$ & 0.649 & 0.651 & 0.665 & 0.649 & 0.666 \\
\hline
\end{tabular}

Notes. See Appendix for data on drug-trafficking organizations. DTOs is the number of cartels that are operating in State $s$ and year $t$. Sinaloa and Zetas are the shares of the state in which these DTOs operate. Share is defined as total number of municipalities where they operate over total number of municipalities in that state. All regressions control for precipitation. Standard errors clustered at the state level in parenthesis. Levels of significance are reported as ${ }^{* * *} \mathrm{p}<0.01,{ }^{*} \mathrm{p}<0.05,{ }^{*} \mathrm{p}<0.1$, ${ }^{+} \mathrm{p}<0.11$. 
Table A.6: Temperature and suicides in Mexico

\begin{tabular}{lccc}
\hline \hline Dependent variable: & \multicolumn{3}{c}{ Suicides } \\
\cline { 2 - 4 } & $(1)$ & $(2)$ & $(3)$ \\
& & & \\
Temperature & $0.007^{* * *}$ & $0.007^{* * *}$ & $0.009^{* *}$ \\
& $(0.001)$ & $(0.001)$ & $(0.003)$ \\
& {$[7.4]$} & {$[7.2]$} & {$[8.7]$} \\
Precipitation & -0.053 & -0.034 & -0.040 \\
& $(0.039)$ & $(0.038)$ & $(0.047)$ \\
& {$[-1.3]$} & {$[-0.8]$} & {$[-1.0]$} \\
Mean of dep. variable & 0.321 & & \\
(Within st. dev.) & $(0.167)$ & & \\
State F.E. & Yes & Yes & Yes \\
Year F.E. & Yes & Yes & Yes \\
Month F.E. & No & Yes & No \\
Month-state F.E. & No & No & Yes \\
State trends & No & Yes & No \\
Observations & 6,528 & 6,528 & 6,528 \\
$\mathrm{R}^{2}$ & 0.470 & 0.490 & 0.499 \\
\hline \hline
\end{tabular}

Notes. Estimates for all 32 states in Mexico in period 1990-2006. State trends is a complete set of linear trends interacted with state indicators. Standard errors clustered at the state level in parenthesis. Standardized effects in brackets. Levels of significance are reported as ${ }^{* * *} \mathrm{p}<0.01,{ }^{* *} \mathrm{p}<0.05,{ }^{*} \mathrm{p}<0.1$. 


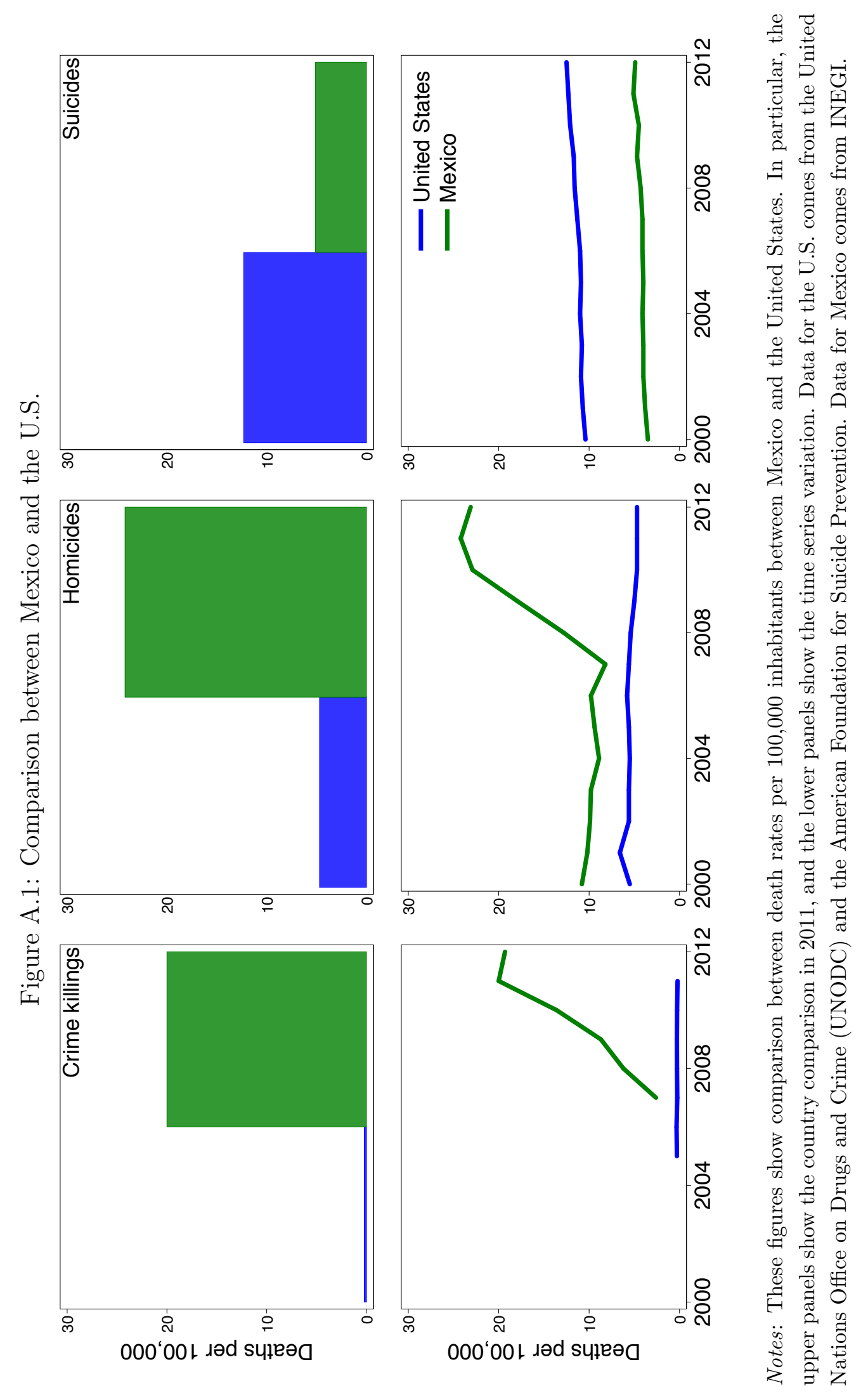


Figure A.2: Geographic distribution of estimates

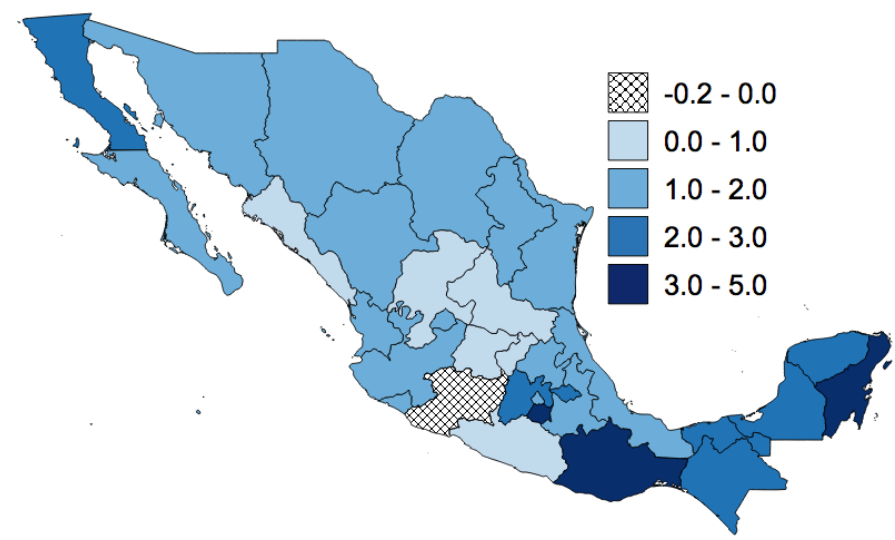

(a) DTO killings

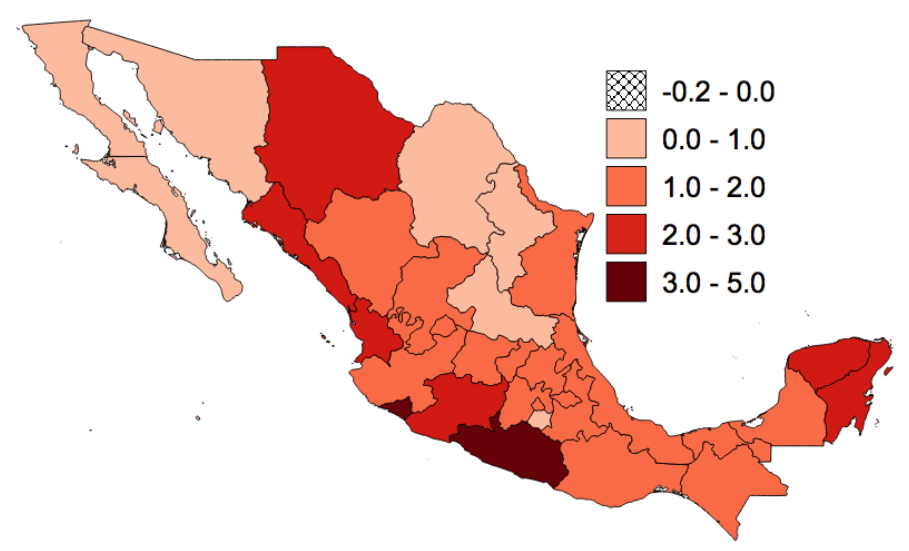

(b) Homicides

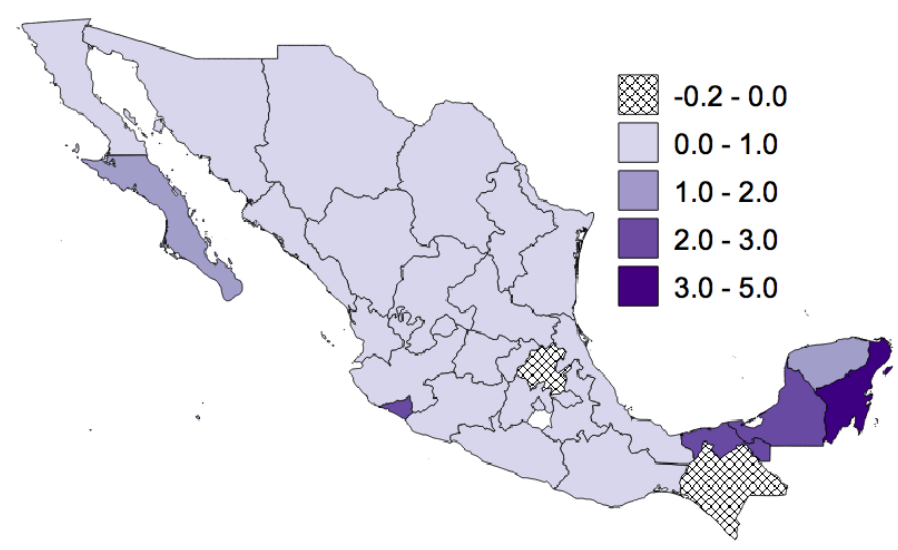

(c) Suicides

Notes: Estimated effect of temperature on the outcome of interest for each state in Mexico. Coefficients are expressed as percentage of the average coefficient for comparison across maps. Categories in these maps correspond to intervals of the same size. Darker colors for larger coefficients. States colored in gray indicate a negative estimated coefficient. 
Figure A.3: Classification of violent DTO

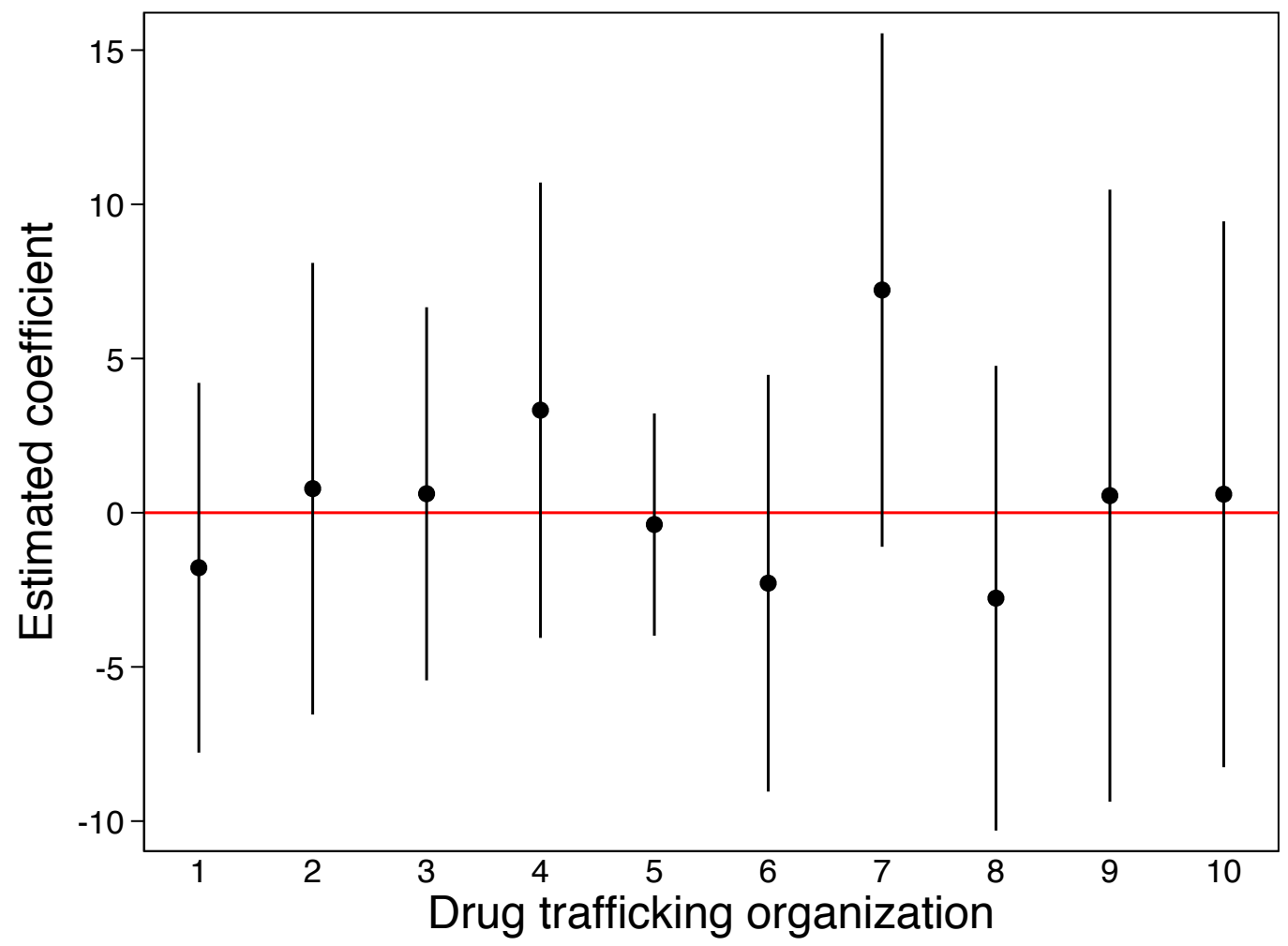

Notes: This figure presents estimates $\beta_{k}$ of the following equation:

$$
\mathrm{y}_{s t}=\alpha+\lambda_{t}+\zeta_{s}+\sum_{k=1}^{10} \beta_{k} D T O_{k s t}+\varepsilon_{s t}
$$

Where $y_{s t}$ is DTO killings for each 100,000 inhabitants, $\alpha$ is a constant term, $\lambda_{t}$ is a year fixed effect, $\zeta_{s}$ is a state fixed effect, $D T O_{k s t}$ are ten indicator variables, and $\varepsilon_{s t}$ is an error term clustered at the state level. According to our definition, DTO number 7 is then classified as violent. 
Figure A.4: Distribution of temperature
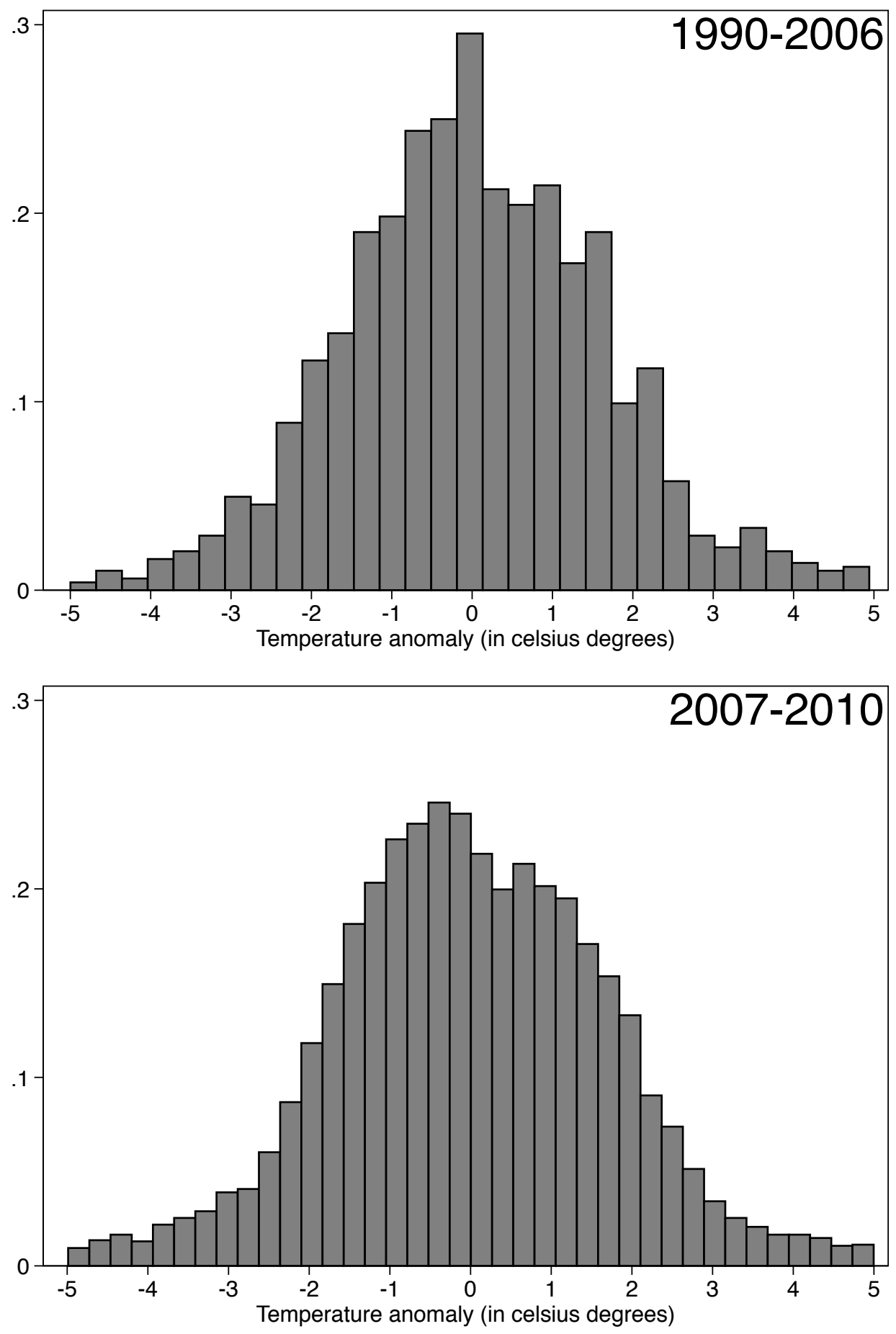

Notes: This figure presents the distribution of temperature - net of state, year, and month fixed effects - for (A) the period from January of 1990 to December of 2006, and (B) the period from January of 2007 to December of 2010. 
Figure A.5: Effects of leads and lags of PROGRESA transfers

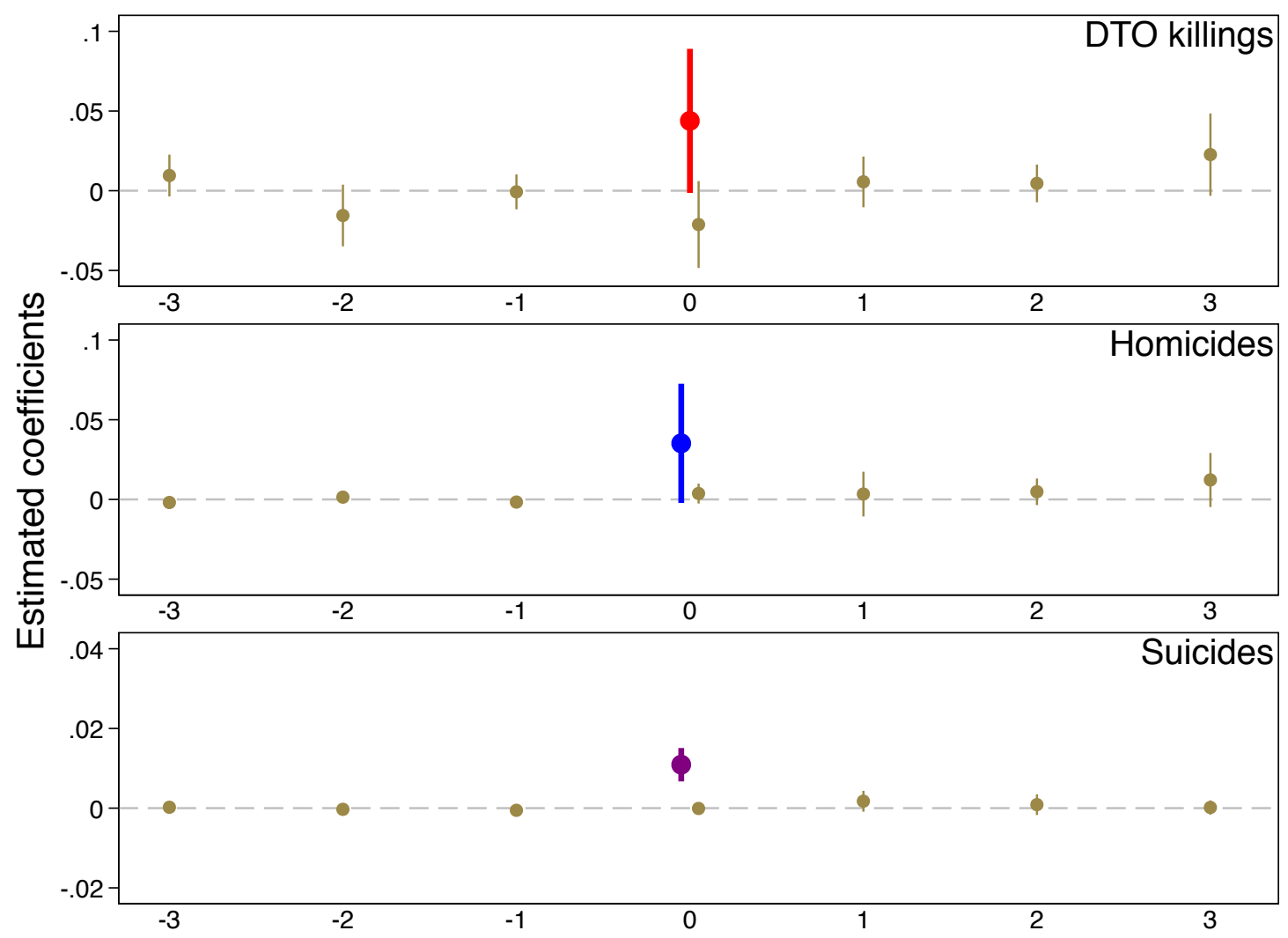

Notes: This figure presents estimates of the following regression:

$$
\begin{aligned}
y_{s m t}= & \alpha+\beta \text { Temp }_{s m t}+\delta \text { Precip }_{s m t} \\
& +\sum_{k=-3}^{3}\left[\gamma_{k}\left(\text { Progresa }_{s(m+k) t} \times \operatorname{Temp}_{s m t}\right)+\phi_{k} \text { Progresa }_{s(m+k) t}\right] \\
& +\lambda_{t}+\xi_{m}+\zeta_{s}+\varepsilon_{s m t}
\end{aligned}
$$

where everything is defined as in the main text, and Progresa ${ }_{s(m+k) t}$ is the logarithm of Progresa transfers in state $s$, month $m+k$, and year $t$. The main effect of temperature on DTO killings, homicides, and suicides (i.e. $\beta$ ) is plotted with the corresponding color we use in the paper. In addition, this figure presents the effects of progresa transfers three months before and after, interacted with temperature, i.e. $\left(\gamma_{-3}, \gamma_{-2}, \gamma_{-1}, \gamma_{0}, \gamma_{1}, \gamma_{2}, \gamma_{3}\right)$. 
Figure A.6: Economic variables and estimated effects by month
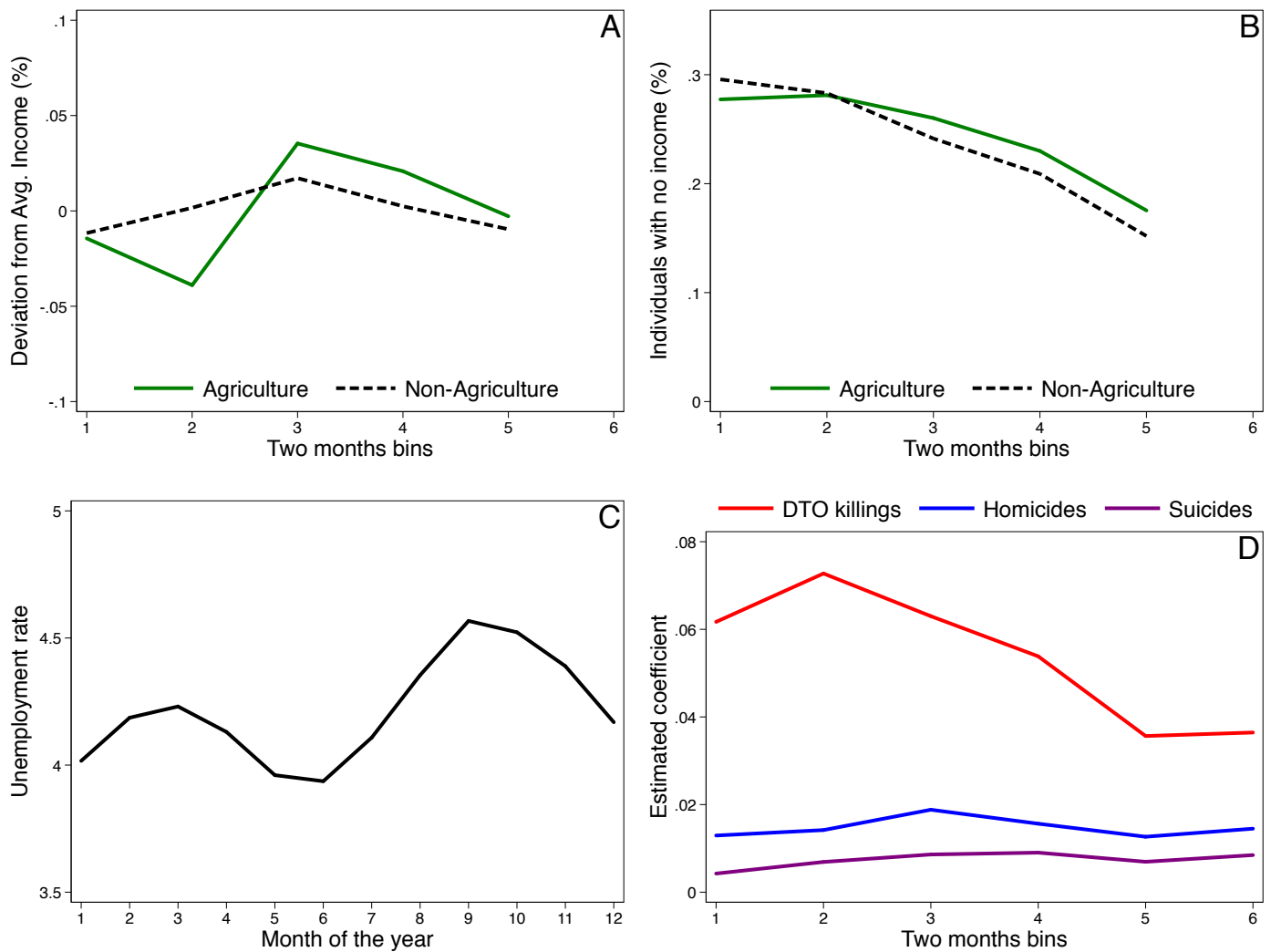

A Deviation (in \%) from average wage for agricultural and non-agricultural workers for two months bins (e.g. bin 1 is January and February). Data for November and December is missing. B Percentage of individuals with wage equal to zero in agricultural and non-agricultural sectors. $\mathbf{C}$ National unemployment rate by month using data from the National survey of occupation (Encuesta Nacional de Ocupación y Empleo), available monthly since 2005. D Estimated effect of temperature in a particular month on the outcome on interest. 